\title{
Article \\ Plenty of Fish in the Sea: Divorce Choice and the Quality of Singles
}

\author{
Giorgio Gronchi ${ }^{1,+}\left(\mathbb{D}\right.$, Elena Parilina ${ }^{2,+}\left(\mathbb{D}\right.$ and Alessandro Tampieri ${ }^{3, *}$ (i) \\ 1 Section of Psychology—Department of Neuroscience, Psychology, Drug Research and Child's Health \\ (NEUROFARBA), University of Florence, 50121 Florence, Italy; giorgio.gronchi@unifi.it \\ 2 Faculty of Applied Mathematics and Control Processes, Saint Petersburg State University, \\ 199034 St. Petersburg, Russia; e.parilina@spbu.ru \\ 3 Department of Economics and Business, University of Florence, 50121 Florence, Italy \\ * Correspondence: alessandro.tampieri@unifi.it; Tel.: +39-055-275-9631 \\ + These authors contributed equally to this work.
}

check for

updates

Citation: Gronchi, G.; Parilina, E.; Tampieri, A. Plenty of Fish in the Sea: Divorce Choice and the Quality of Singles. Mathematics 2021, 9, 3059. https://doi.org/10.3390/math9233059

Academic Editor: Vasile Preda

Received: 1 November 2021

Accepted: 26 November 2021

Published: 28 November 2021

Publisher's Note: MDPI stays neutral with regard to jurisdictional claims in published maps and institutional affiliations.

Copyright: (c) 2021 by the authors. Licensee MDPI, Basel, Switzerland. This article is an open access article distributed under the terms and conditions of the Creative Commons Attribution (CC BY) license (https:/ / creativecommons.org/licenses/by/ $4.0 /)$.

\begin{abstract}
In the literature of marriage, divorce choices are usually assumed to not affect the distribution of types in the pool of singles. The scope of the present paper is to overcome this assumption. We analyse divorce choices when separation decision influences the distribution of singles and, thus, their expected quality. We consider a three-period model where heterogeneous individuals may unilaterally experience divorce and return to the marriage market. The choices of individuals are based on the change in the distribution of singles and the cost of waiting and divorcing, taking into consideration the individual's eligibility in the marriage market. There are two main findings: Firstly, positive assortative matching dissolves with divorce for some intermediate types. Therefore, the endogenous positive assortative matching that usually emerges in models with nontransferable utility is weakened when matches can dissolve. Secondly, the existence of ranges where divorce emerges among individuals with positive assortative matching implies the existence of two disconnected classes of types. If matchings in the first period were to occur between individuals of different classes, such matches would be dissolved later.
\end{abstract}

Keywords: non-stationary distribution; divorce cost; waiting cost

JEL Classification: J12; C78

\section{Introduction}

The study of decision making is a highly diverse and interdisciplinary domain, including psychology, mathematics (in particular, game theory), economics and, more generally, the entire fields of social and behavioural sciences [1-4]. This paper examines divorce and the search for a partner: This is a prototypical example of search-and-matching behaviours, a topic mainly investigated in economic literature and usually neglected by psychology [5,6]. Generally speaking, search-and-matching behaviours refer to situations where an individual is looking for some forms of long-term status (searching for a partner, searching for a job and so on). Achieving this state is connected to the availability and the quality of the possible matches. Here, we will focus on divorce choice. The theoretical analysis is then followed by an empirical test of some predictions of the model. Finally, implications for psychology, generalisation to other domains and the role of legislation in divorce decisions are discussed.

This paper analyses divorce choice when marital choices influence the population of singles. In the economic literature, divorce has been treated extensively [7-14] by using very different perspectives (refer to the Related Literature section for details). In particular, the analysis of search and matching in marriage markets and the steady state requires that the number of divorces must equate to the flow creation of matches for every type [14]. This 
condition ensures that the distribution of singles remains constant over time. This approach sets aside the fact that the distribution of singles affects marriage and divorce decisions.

For instance, imagine that high-type individuals, if matched together, marry without any delay. Their behaviour could quicken their marriages compared to other individuals of lower types, and with higher exit rates, they number relatively fewer in the pool of unmatched singles. The composition of singles will then change, and individuals in a couple will use this information, in turn, to evaluate whether to stay in their marriage or not.

Thus, the analysis of divorce choice requires departing from the steady-state analysis: endogenous divorce decisions depend on the quality of potential partners, which in turn depends on which individuals marry and leave the marriage market. Hence, the changes in the distribution of singles affect divorce decisions. The relevance of taking into account these factors is testified by the vast amount of empirical evidence focused on the influence of the context in cognitive processing and, in particular, decision making [15-18].

In this paper, we try to fill this gap in research. We analyse divorce choice when the distribution of singles is non-stationary. We take into account a three-period game where individuals are uniformly distributed in one characteristic, equally evaluated by all, called "quality". In the first period, each individual randomly meets one potential partner, and they both decide whether to marry or not. If a marriage does not occur, the random match is repeated in the second period with the same rules. Conversely, an individual who married in the first period may divorce the partner in the second period and re-enter the marriage market during the same period. Divorce entails an explicit cost. In the last period, there is again a random matching for singles, but now couples cannot divorce. Individuals adopt threshold strategies by comparing the met person (for marriage decisions) or the spouse (for divorce decisions) with the expected quality of singles. Marriage and divorce choices modify the distribution of singles and, thus, their expected quality in the marriage market.

We investigate the existence of "divorce" equilibria where divorcing is sufficiently cheap and everyone can afford it. Of course, when the divorce cost is too high, no one will undergo divorce. Otherwise, the interconnection between divorce costs and the implicit cost of waiting for future partners determines the features of the divorce equilibria. If divorce costs are low, "rational divorce" occurs: This happens when, in the first period, individuals accept a non-optimal partner to avoid loneliness but are already planning a future divorce. Conversely, a high cost of waiting decreases the discounted value of future matches. More specifically, if the cost of waiting is high, then there is a stronger incentive in agreeing to match whatever potential partner is met after divorce. A risk of "downgrading" appears: a high-quality person who divorced the partner may end up with a partner that is worse than the divorced one. In the case of a very high waiting cost, divorce does not emerge due to avoiding the risk of downgrading. Divorce occurs with a certain degree of asymmetry among spouses' types or between some symmetric, medium-type spouses.

The paper then considers two equilibria where divorce is affordable only for one class of individuals. Intuitively, this reduces the frequency of divorce. A numerical analysis of existence shows that each of the three admissible equilibrium configurations is unique in its region of existence. A robust finding on all equilibria configurations includes the existence of two disconnected classes of types: a highest class and an intermediate class. Permanent marriages arise only upon meeting within one's class. If matchings were to occur with individuals from different classes, divorce would occur at a later stage.

The analysis is then extended by considering the entry of a younger generation in the second period in a simplified model with two periods. In line with empirical evidence $[19,20]$, the presence of younger singles increases the probability of divorce. Next, we test our theoretical results by using a simple empirical test, where evidence on divorce seems consistent with our theoretical results. We then discuss how our theoretical results can be linked to the debate in the field of psychology, to other social contexts and to the evolution of divorce legislation over the past few decades. 
Our contribution is aimed at increasing the theoretical understanding of divorce decisions and how these decisions affect the marriage market. In models where divorce is admissible and free of charge, individuals have an incentive in choosing the potential partner they meet given an implicit cost of waiting. Naturally, a non-optimal partner can be discarded if there is a good chance of finding a better partner in the future [21,22]. The introduction of an explicit divorce cost changes the person's behaviour: an individual agrees to marry either if he/she likes the potential partner or if the benefit of staying with the partner will offset future divorce costs.

The remainder of the paper is organised as follows. The next section briefly summarises some related literature. Section 3 introduces the theoretical model, while Section 4 outlines baseline results. Section 5 introduces the entry of younger singles, and Section 6 proposes a simple correlation to find some consistency in our results on divorce patterns. Section 7 discusses our findings with respect to psychology, to other possible applications and to divorce legislation, while Section 8 provides our conclusions. Figure 1 summarises the roadmap of this paper.

\section{Flow Chart}

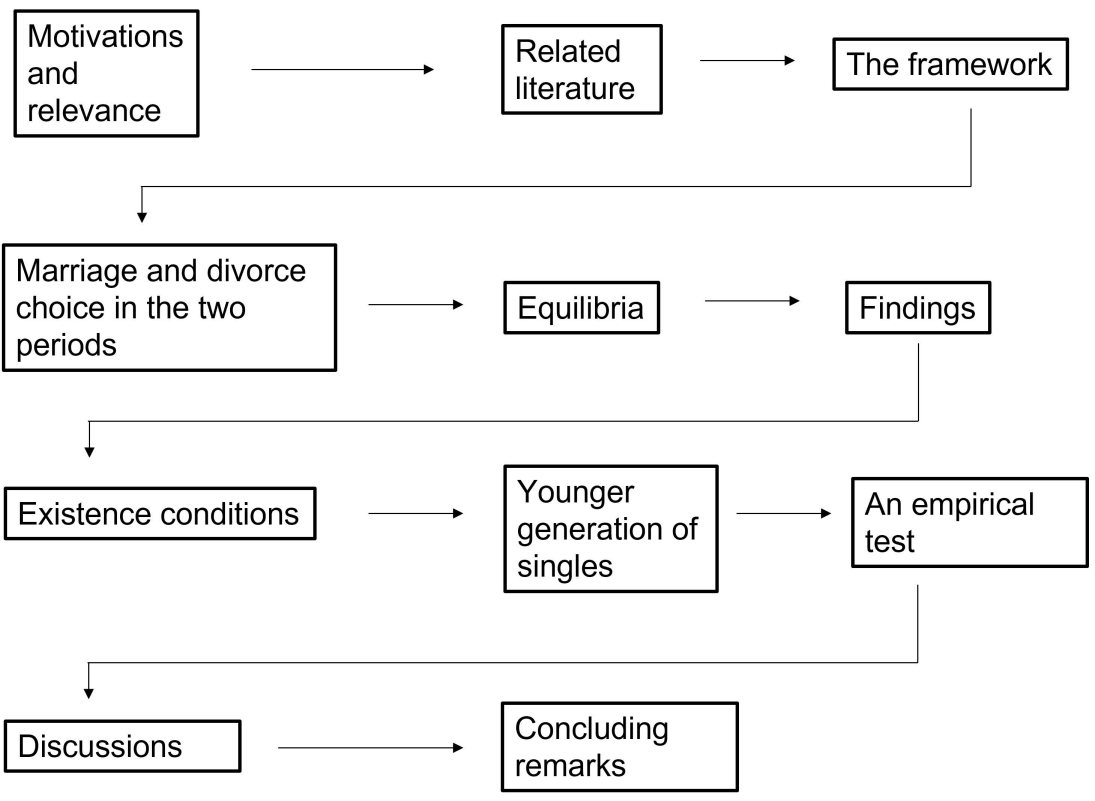

Figure 1. Roadmap of this paper.

\section{Related Literature}

The following brief synthesis of related literature refers to the four strands of economics literature: the literature on non-stationary dynamics, the literature on matching with nontransferable utility, the literature on divorce and the literature on optimal stopping.

Non-stationary dynamics. Models with non-stationary dynamic are rare due to their limited analytical tractability. Smith [23] pioneered this approach: He investigated a matching model where non-steady state dynamics are driven by temporary matches that occur because of an implicit cost of waiting. Shimer and Smith [24] evaluated whether search and matching efficiency requires non-stationarity. Damiano et al. [25] examined nonstationary dynamics and sorting efficiency in a two-period matching model. If individuals incur participation costs and the space of types is sufficiently large, the market unravels as almost all individuals rush to participate in the first period and match whatever potential partner they meet.

In this line of research, the latest development results from a study conducted by Bonneton and Sandmann [26]. They analysed non-stationary dynamics with heterogeneous 
agents and non-transferable utility. They observed that higher-type individuals are less risk averse. They also prove the existence of non-stationary equilibria.

The present paper is linked to the discrete-time, three-period version of Smith [23]. In Smith [23], divorcing does not entail an explicit divorce cost, but it makes an individual lose his or her turn in the marriage market. Thus, divorce occurs for low types, since the implicit cost of losing one turn is very high for high types because they are "eligible" (i.e., they are a good catch). Compared to Smith [23], a divorced person re-enters the marriage market in the same period; that is, divorcing does not cause the person to lose any turns. In addition, divorcing entails a cost that increases with an individual's type. Unlike Smith [23], divorce is more appealing for medium-high types. This happens even if the total cost of divorce is higher for higher types, since the cost of divorce remains relatively higher for low and ineligible types.

Matching models with non-transferable utility. There are many relevant contributions to this literature [27-33]. A typical result in these studies is "block segregation": During equilibrium, positive assortative matching emerges where an interval of individuals of the highest type matches only with each other, and the next highest match occurs only with each other and so forth. By adopting a general payoff function, Smith [32] finds that block segregation emerges with any multiplicatively separable payoff function. The author finds a set of conditions under which block segregation disappears.

Similarly to these models where divorce is banned, we find a block segregation result adjusted by the divorce option. The main difference is the fact that, in those settings, the distribution of singles is stationary. In our model, the reservation payoff in a certain period depends on the expected quality of singles in the next period, which changes over time according to marriage and divorce decisions.

Goldmanis et al. [22] extended Smith's paper [32] by allowing individuals to keep looking for better partners while they are married. Unlike the present analysis, they analyse the system in a steady-state, thus assuming stationary distribution of singles and no divorce costs. Steady-state occurs by assuming that agents adopt the strategy to accept everyone when single and to undergo a divorce when a better partner is found. In the present paper, the presence of divorce costs prevents the strategy to accept any potential partner as optimal.

Divorce. In the recent years, divorce has been analysed in relation to household labour supply [10], the choice between marriage and cohabitation [11] and investment in marriagespecific capital, such as buying a house, having children, dividing home versus market work $[12,13]$ and the access to broadband and cell phones [34]. For a thorough review of the developments of the literature of marriage markets and divorce, refer to Chiappori [35].

Within economics, divorce is commonly explained by using three arguments. The first is that divorce is a result of an unexpected matching shock. A second argument is the imperfect information about the true type of the other individual and learning upon matching. These two arguments are often examined together or as alternative explanations [36]. The third argument for divorce is that a temporary but not optimal match is more convenient than being alone: Individuals may marry a partner even if he or she is not satisfactory in order to not be alone [21,37]. Our model is somewhat linked to the last explanation: temporary matches are more convenient than being alone, but we bind this choice by adding an explicit cost of divorce.

In Chiappori and Weiss [21], divorce was examined in a general equilibrium model with a homogeneous population: In the first period, everyone marries regardless of the quality of the match. Divorced individuals always remarry if they meet a new partner, and there is no divorce cost. Instead, we assume the population to be heterogeneous, and a further choice on remarriage is permitted. More recently, Bolletta and Merlino [38] analysed marriage formation in a setting where divorce occurs with exogenous probability. In their model, individuals might meet potential spouses directly or through their friends, and in this case socialisation matters for determining marriage outcomes. 
In the frameworks described so far, divorce has been modelled exogenously. Our framework differs from these studies mainly because it assumes divorce as an endogenous choice that affects the distribution of singles.

On this point, there exists a line of research that established the existence of a sorting externality on both partnership [27] and separation strategies [28]: the matching and divorcing strategies of individuals affect the endogenous distribution of types in the pool of unmatched singles. In particular, Burdett and Coles [28] consider a model with continuous time, two types of individuals, which consist of one good and one bad companion, and either zero or very large separation costs. The present paper extends this research by considering a continuum of types rather than two and discrete rather than continuous time and focuses on the differences in divorce costs: as it will be clear shortly, we assume that divorce costs are proportional to an individual's type.

Optimal stopping. From a mathematical perspective, our paper can be linked with the literature on optimal stopping, which is when the decision maker chooses a moment to stop and obtains benefits by taking into account uncertainty about possible future outcomes [39]. The applications of such models are numerous, including an optimal job search (two-sided), selling and buying assets, purchasing long-term assets such as apartments, cars, etc. [40,41]. In our model, the decision maker is assumed to be rational when making decisions in optimal stopping problems and when choosing the strategies to marry or to divorce by comparing his/her utilities under different scenarios.

\section{The model}

\subsection{A Three-Periods Game with Random Match}

The model extends the three-periods model by Smith [23] by adding, together with the waiting cost, the explicit divorce cost. An acronym list is reported in Table 1 . There are two populations of the same size: one of individual's $i$ and one of partner's $p$. Each population is a continuum with types $\theta$ that are equally distributed uniformly in $[0,1]$ and living in three periods. In every period, each individual $i$ (he) is randomly matched with one potential partner or "pretender" $p$ (she) with only one random draw. In the following analysis, we will maintain the point of view of individual $i$, but the problem of a pretender is symmetric. Either party can refuse the match in the first two periods, while in the third period the match is compulsory: The interpretation is that older individuals prefer to spend the last years of their life with someone, whoever they will be, rather than being alone. If both an individual and a pretender agree to match, the couple obtains a flow utility of $2 \theta_{i} \theta_{p}$, where $\theta_{i}$ is the individual's type and $\theta_{p}$ is the partner's type. If at least one refuses the match, each obtains zero flow utility. Spouses equally share the flow utility such that the individual $i$ 's flow utility defined as follows per period:

$$
u_{i}\left(\theta_{i}, \theta_{p t}\right)=\theta_{i} \theta_{p t}
$$

where $\theta_{p t}$ is the type of pretender met in period $t \in\{1,2,3\}$. Given that everyone benefits from a larger $\theta$, the type represents an individual's feature that is ranked in the same way by everyone. Thus, each individual prefers to be matched with a partner of type $\theta_{p t}^{\prime}=\theta^{\prime}$ rather than with a partner of type $\theta_{p t}^{\prime \prime}=\theta^{\prime \prime}$ as long as $\theta^{\prime}>\theta^{\prime \prime}$. Thus, a type may represent, for example, an individual's education, income, health status or, more generally, his "quality". What is noteworty is that since the utility function is multiplicatively separable, a person's parameter does not affect preferences, and all individuals share the same decision criterion.

In the flow utility (Equation (1)), we do not consider a hypothetical idiosyncratic benefit that may represent, for instance, "love" or some subjective preferences. A method to consider this aspect is by adding a second, additive component of flow utility and by assuming that it is IID among individuals with zero mean. If implemented along these lines, this feature would not influence the individuals' decisions and may be omitted for the sake of simplicity. 
Moreover, we assume that individual types are constant over time. Actually, this may be the case if a type is determined by the level of education, as marriage usually occurs after schooling. Education may also predict, on average, future levels of income.

Figure 2 shows the timing of the game, together with the total utility according to matching outcomes. We begin from the case in which the individual rejects his pretender in $T=1$. In this case, he proceed to the marriage market in $T=2$. Accepting the marriage in $T=2$ implies remaining married forever, while rejecting a marriage in $T=2$ results in a random match with mandatory acceptance in $T=3$.

Consider next the more complex situation where an individual accepts the match in $T=1$. After agreeing to marry, the individual may divorce the partner in $T=2$ at a cost $c \theta_{i}$, with $c \in(0,1)$, and return to the marriage market during the same period. This is another difference compared to Smith [23] in which divorcees must wait one period before re-entering the marriage market. Since we are assuming that any time period is quite long considering a loving life of three periods, our assumption seems natural.

Table 1. Acronym list.

\begin{tabular}{|c|c|}
\hline \multicolumn{2}{|l|}{ Subscripts } \\
\hline \multirow{5}{*}{$\begin{array}{c}i \\
p \\
t \in\{1,2,3\} \\
d \\
e\end{array}$} & Individual (he) \\
\hline & Partner (she) \\
\hline & Time periods \\
\hline & "Cheap" divorce \\
\hline & "Expensive" and "highly expensive" divorce \\
\hline \multicolumn{2}{|c|}{ Parameters and payoffs } \\
\hline$\theta \in[0,1]$ & Continuum of individual/partner types \\
\hline$T \in\{1,2,3\}$ & Time periods \\
\hline$c \in(0,1)$ & Divorce cost parameter \\
\hline$\delta \in(0,1)$ & Per-period discount rate \\
\hline$u_{i}\left(\theta_{i}, \theta_{p t}\right)=\theta_{i} \theta_{p t}$ & Individual $i$ 's flow utility at time $t$ if matched with partner $p$ \\
\hline$c \theta_{i}$ & Divorce cost of individual $i$ \\
\hline \multicolumn{2}{|l|}{ Thresholds } \\
\hline$\widehat{\theta}$ & Expected quality of singles in $T=3$ \\
\hline$\widetilde{\theta}$ & Expected quality of singles in $T=2$ \\
\hline$\widetilde{\theta}_{2 T}$ & Expected quality of singles in the two-period model without new generation \\
\hline$\tilde{\theta}_{\text {over }}$ & Expected quality of singles in the two-period model with new generation \\
\hline$\Phi_{1}$ & Divorce threshold given by the expected quality of singles in $T=2$ \\
\hline$\Phi_{2}$ & Divorce threshold given by the expected quality of singles in $T=3$ \\
\hline$\Phi_{3}$ & Inactive divorce threshold \\
\hline$\Phi_{4}$ & Divorce threshold for the existence of the expensive divorce configuration \\
\hline \multicolumn{2}{|c|}{ Notation in Figures 2, 3, 9 and A1-A3 } \\
\hline$m$ & Individual/partner who marries in $T=1$ for life; \\
\hline$r$ & Individual/partner who rejects her/his potential partner in $T=1$ \\
\hline$d$ & Individual/partner who divorces her/his spouse in $T=2$ \\
\hline
\end{tabular}

The assumption that the cost of divorce increases with respect to individual type is particularly fitting when the interpretation type focuses on "income": Individuals differing in income pay substantially different costs of divorce. Note that divorce is possible only in $T=2$. Once the divorced individual has met his new pretender, he may then agree or not to the new match. Finally, we assume that divorced individuals do not know the new pretender met in $T=2$ when they decide to divorce their spouses (i.e., no "affairs" are allowed). 


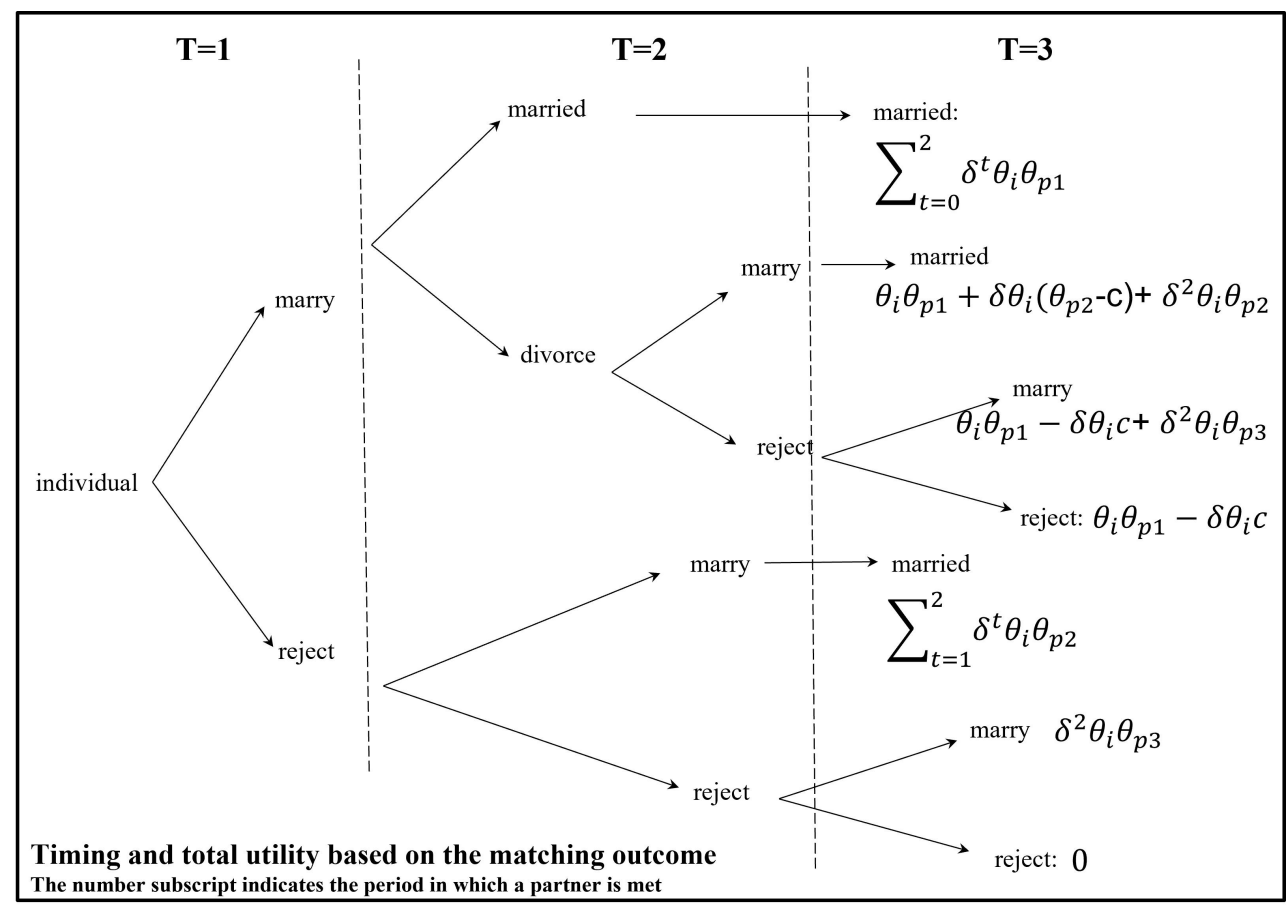

Figure 2. Timing and total utilities.

In his marriage and divorce decisions, an individual $i$ takes into account the following two factors:

1. The pretender/spouse's type $\theta_{p t}$ : each individual would like to increase the partner's quality as much as possible;

2. His type $\theta_{i}$ : an individual type determines his "eligibility" in the future, that is, the chances of being chosen in the marriage market. For example, if the individual is of low quality, then he knows that high-quality pretenders will refuse him. Thus, he is likely not to divorce his partner even if he prefers a better one.

These two points will be discussed more in detail below. We assume that individuals adopt threshold strategies: When they are singles and must choose whether or not to marry, they observe the discounted expected payoff provided by future singles and compare it with the payoff provided by their pretender. Let the per-period discount rate be $\delta<1$. In this context, we may interpret $\delta$ as an inverse measure of the cost of waiting: If $\delta$ is low, it is more likely that a pretender met today is of higher quality than the expected quality of singles in the next period. When they are married and must choose whether or not to proceed with divorce (in $T=2$ ), they observe the expected quality of singles in the same period net of the divorce cost. In both cases, they take into account their future eligibility by comparing their quality with the discounted expected quality of singles in the next period. Notice that the analysis of a three-period game is necessary in order to precisely take into account the role of eligibility in the divorce choice. If the game lasted two periods and the mandatory match was at $T=2$ instead and still permits ending the relationship that began in $T=1$, then the divorce choice would only be based on the quality of the partner compared to the average quality in the market (a two-period framework is considered in Section 5).

We solve the game by backward induction, starting from Period 2 since no choice is allowed in Period 3.

\subsection{Period 2}

In $T=2$, single and divorced individuals choose whether or not to accept their match based on the expected quality of singles in $T=3$, denoted as $\widehat{\theta}$ ( singles in $T=3$ either (i) rejected/were rejected by their pretenders both in $T=1$ and $T=2$ or (ii) married in $T=1$, 
divorced in $T=2$ and rejected/were rejected by the pretenders met in $T=2$ ). In particular, they compare the payoff obtained by the pretender met in $T=2, \theta_{p 2}$, with the payoff obtained by the expected partner in $T=3$ : A partner met in $T=2$ is accepted ifthe interpretation of the type is "income": Individuals differing in income pay substantially different costs of divorce. Note that divorce is possible only in $T=2$. Once the divorced individual has met his new pretender, then he may agree or disagree with the new match. Finally, we assume that divorced individuals do not know the new pretender met in $T=2$ when they decide to divorce their spouses (i.e., no "affairs" are allowed).

$$
\theta_{i} \theta_{p 2}(1+\delta)>\theta_{i} \delta \widehat{\theta} \Leftrightarrow \theta_{p 2}>\frac{\delta \widehat{\theta}}{1+\delta} .
$$

Hence, $\frac{\delta \widehat{\theta}}{1+\delta}$ is the threshold strategy for the second period.

Conversely, individuals are married in $T=2$ if they are accepted by their pretenders in $T=1, \theta_{p 1}$. Their divorce choice depends on the comparison between the spouse met in $T=1$ and the expectation of partners in the marriage market. If $\theta_{p 1}$ does not yield a sufficiently high payoff compared to the expectations, an individual is "unhappy". Moreover, divorce depends on the chance to be accepted in $T=2$ to which we refer as "eligibility".

\subsubsection{Unhappiness}

At the beginning of $T=2$, married individuals observe the expected quality of singles in $T=2$. The expectation is denoted by $\widetilde{\theta}$, and by using this an individual can compare the expected benefit obtained by divorcing with the expected benefit obtained by staying married. In particular, they undergo divorce if the following is the case.

$$
\theta_{i} \theta_{p 1}(1+\delta)<\theta_{i}[\widetilde{\theta}(1+\delta)-c] \Leftrightarrow \theta_{p 1}<\widetilde{\theta}-\frac{c}{1+\delta} \equiv \Phi_{1} .
$$

Note that expectation $\widetilde{\theta}$ takes into account divorce decisions: a married individual foresees that certain individuals divorce in $T=2$ (assuming "myopic" individuals would yield qualitatively similar results). Moreover, even if assuming that they do not make a match in $T=2$, they may prefer to proceed with divorce if the expected discounted type in $T=3$ is sufficiently large and particularly if the following is satisfied.

$$
\theta_{i} \theta_{p 1}(1+\delta)<\theta_{i}(\widehat{\theta} \delta-c) \Leftrightarrow \theta_{p 1}<\frac{\delta \widehat{\theta}}{1+\delta}-\frac{c}{1+\delta} \equiv \Phi_{2}
$$

\subsubsection{Eligibility}

The unhappiness condition also depends on an individual's "eligibility" in the marriage market. Individual $i$ is considered "eligible" if accepting him in $T=2$ yields a higher payoff than waiting for the mandatory match in $T=3$.

$$
\theta_{p 2} \theta_{i}(1+\delta) \geq \theta_{p_{2}} \delta \widehat{\theta} \Leftrightarrow \theta_{i} \geq \frac{\delta \widehat{\theta}}{1+\delta} .
$$

If an individual is eligible, his condition of unhappiness is (3) or (4) since he expects to be accepted in the $T=2$ match. In this case, unhappiness occurs if the following is the case.

$$
\theta_{p 1}<\max \left\{\Phi_{1}, \Phi_{2}\right\}
$$

Conversely, a non-eligible individual $\left(\theta_{i}<\frac{\delta \widehat{\theta}}{1+\delta}\right)$ will not be accepted in $T=2$. Nevertheless, he may find it convenient to divorce his partner, lose the $T=2$ payoff and obtain a match in $T=3$. This occurs if condition (4) holds. 


\subsection{Period 1}

In the first period, an individual chooses whether to marry or reject the match. The decision depends on two elements: the expectations on choices in $T=2$ and the divorce cost.

\subsubsection{Expectations on the Future}

The choice in the first period depends on whether an individual, if married, expects to stay married with the partner she meets today or to divorce him and, if single, expects to match in $T=2$ or $T=3$. This expectation depends on an individual's unhappiness and eligibility as determined in the previous section. In particular, an individual must compare the payoff of rejecting the match with the payoff of marrying for life or marrying and divorcing. The latter depends on whether $\theta_{p 1}$ is larger or smaller than $\Phi_{1}$ or $\Phi_{2}$ according to the situation (see the section above). Therefore, an individual's eligibility and partner's quality determine different subgames in $T=2$; thus, we need to define the optimal behaviour in the first period for each of them.

\subsubsection{Divorce Option}

The second element that determines the individual's choice in the first period is whether the discounted divorce cost is lower than the current payoff of marrying the pretender in $T=1, \theta_{p 1}>\delta c$. This point deserves some discussion.

An individual may accept a pretender even if she makes him unhappy $\left(\theta_{p 1}<\max \left\{\Phi_{1}, \Phi_{2}\right\}\right)$ if her quality is not lower than the discounted divorce cost, $\theta_{p 1} \geq \delta c$, since the cost of divorce is offset by the payoff provided from the partner's type. This strategy can be defined as "rational divorce": if $\theta_{p 1} \in\left(\delta c, \max \left\{\Phi_{1}, \Phi_{2}\right\}\right)$, an individual can marry a pretender even if planning a future divorce. At the limit, for $c=0$, it is optimal to marry the pretender in $T=1$ in order to obtain the payoff in $T=1$ and also because it is costless to divorce her in the second period to find someone better.

The consequence of the divorce option is that, in $T=1$, an individual decides to marry by comparing the pretender's $\theta_{p 1}$ with $\delta c$ instead of $\widetilde{\theta}$. Hence, the expected discounted quality is not relevant in $T=1$ because divorce is sufficiently cheap such that the individual can leave the pretender in the next period and obtain a net benefit $\theta_{p 1}-\delta c>0$. Therefore, only $\widetilde{\theta}$ plays a role in determining the divorce decision in $T=2$.

\section{Results}

\subsection{Cheap Divorce}

In this section, we outline the baseline results. To begin with, we show the conditions under which divorce is sufficiently cheap to be considered as a possible option for all individuals. For the sake of naming it, we name this equilibrium configuration "cheap divorce". The results change based on whether an individual is eligible or not: It depends on whether individual type $\theta_{i}$ is lower or higher than $\frac{\delta \widehat{\theta}}{1+\delta}$. The divorce conditions can be summarised as follows.

Proposition 1. Suppose $\theta_{i}>\frac{\delta \widehat{\theta}}{1+\delta}$. Then, for $c<\frac{\max \{(1+\delta) \widetilde{\theta}, \delta \widehat{\theta}\}}{1+\delta+\delta^{2}}$, the eligible individual $i$ may choose divorce. Suppose $\theta_{i}<\frac{\delta \widehat{\theta}}{1+\delta}$. Then, for $c<\frac{\delta \widehat{\theta}}{1+\delta+\delta^{2}}$, the non-eligible individual $i$ may choose divorce.

\section{Proof. Refer to Appendix A.}

Proposition 1 implies that, in an equilibrium where divorce occurs, the following relation holds: $\min \left\{\Phi_{1}, \Phi_{2}\right\}>\delta c$. We first outline the equilibrium behaviour of eligible individuals.

Proposition 2. Suppose $\theta_{i}>\frac{\delta \widehat{\theta}}{1+\delta}$. Then, an eligible individual performs the following:

- $\quad$ Marries for life in $T=1$ if $\theta_{p 1}>\max \left\{\Phi_{1}, \Phi_{2}\right\}$; 
- Divorces in $T=2$ if $\theta_{p 1} \in\left(\delta c, \max \left\{\Phi_{1}, \Phi_{2}\right\}\right)$;

- $\quad$ Rejects the match in $T=1$ if $\theta_{p 1}<\delta c$.

Proof. See Appendix A.

Next, the following proposition shows the equilibrium behaviour of non-eligible individuals.

Proposition 3. Suppose $\theta_{i}<\frac{\delta \widehat{\theta}}{1+\delta}$. Then, a non-eligible individual performs the following:

- Marries for life in $T=1$ if $\theta_{p 1}>\Phi_{2}$;

- Divorces in $T=2$ if $\theta_{p 1} \in\left(\delta c, \Phi_{2}\right)$;

- $\quad$ Rejects the match in $T=1$ if $\theta_{p 1}<\delta c$.

Proof. Refer to Appendix A.

Having determined the divorce conditions and equilibrium behaviour, we are in a position to outline the features of an equilibrium where all individual types can afford divorce. The following proposition shows the relationship between $\widetilde{\theta}$ and $\widehat{\theta}$.

Proposition 4. A "cheap" divorce equilibrium is characterised by $\left(\widetilde{\theta}_{d}, \widehat{\theta}_{d}\right)$, where $\frac{\delta \widehat{\theta}}{1+\delta}<\Phi_{1}\left(\widetilde{\theta}_{d}\right)$.

Proof. Refer to Appendix B.

Appendix $C$ provides a formal derivation of $\left(\widetilde{\theta}_{d}, \widehat{\theta}_{d}\right)$. Proposition 4 implies $\frac{\delta \widehat{\theta}}{1+\delta}<\widetilde{\theta}$ : The average quality of singles falls over time, since higher types marry at a faster rate. In addition, together with Proposition 1, it allows inferring the admissible equilibrium configuration in the baseline case where everyone can afford to proceed with divorce.

Remark 1. Propositions 1 and 4 imply that a cheap divorce equilibrium occurs for $\Phi_{1}>\frac{\delta \widehat{\theta}}{1+\delta}>\Phi_{2}>\delta c$.

Figure 3 shows the marriage choices in $T=1$ and the divorce choice in $T=2$. In every region, each couple letter represents the behaviour of agents $i$ and $p 1$, with the first letter indicating the partner's behaviour and the second letter indicating the individual's behaviour. Marriage takes place in $T=1$ and lasts for the entire game if both letters are $m$ (married in $T=1$ for life), while $r$ indicates that one agent rejected the person they met in $T=1$. Thus, for example, an individual $i$ of type $\theta_{i} \in\left(\Phi_{2}, \frac{\delta \widehat{\theta}}{1+\delta}\right)$ agrees to marry a pretender of type $\theta_{p} \in\left(\Phi_{2}, \frac{\delta \widehat{\theta}}{1+\delta}\right)$ and his feelings are reciprocated (letters $m m$ ) but divorces type $\theta_{p 1} \in\left(\delta c, \Phi_{2}\right)$, who instead would be happy to stay married with him (letters $m d$ ) and refuses type $\theta_{p 1}<\delta c$ (letters $m r$ ). The areas where a divorce takes place are those where either both spouses $(d d)$ or only one ( $d m$ or $m d$ ) would like to proceed with divorce.

The straight lines separate the regions in which different outcomes occur. Note that this is a "block segregation" result, which is typical of matching models with non-transferable utility [27-31,40]. In equilibrium, positive assortative matching emerges as only similar individuals marry each other: Individuals agree to marry only with potential partners of the same "block". Compared to the standard block segregation result, agents from the block $r r$ remain single in $T=1$, while agents from blocks $d d$ divorce their partner in $T=2$. 


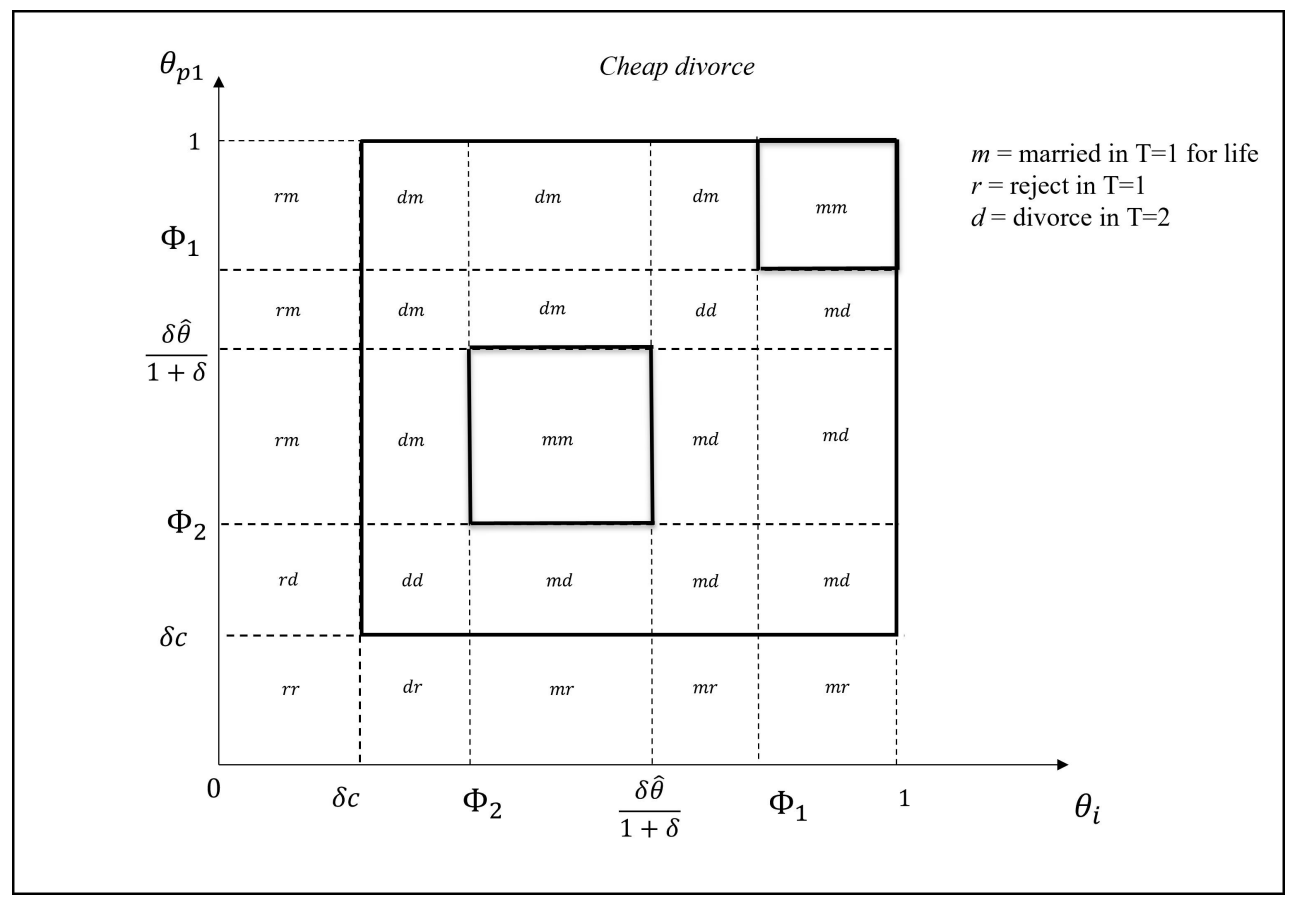

Figure 3. "Cheap divorce" equilibrium configuration—both eligible and non-eligible individuals may divorce.

\subsection{Expensive Divorce}

In the analysis conducted so far, we have outlined the conditions under which divorce is affordable for everyone. This solution does not necessarily apply. There is little evidence on divorce costs: the Huffington Post (2013) suggests that a divorce may cost, on average, between USD 15,000 and USD 20,000 (https: / / www.huffpost.com/entry / how-much-doesthe-average_b_3360433?guccounter=1, access on 1 November 2021). In this model, an increase in $c$ results in an increase in $\delta c$ and a decrease in $\Phi_{1}$ and $\Phi_{2}$. In particular, divorce is not an affordable option if the conditions outlined in Proposition 1 do not hold anymore.

Two configurations emerge, according to the following definitions (see Appendix $C$ for a formal derivation). Notice that the value of $\left(\widetilde{\theta}_{e}, \widehat{\theta}_{e}\right)$ is the same in both configurations (refer to Appendix C); what differs are the conditions under which one configuration holds. For convenience, use the following denotation:

$$
\Phi_{4} \equiv \frac{\delta^{2} \widehat{\theta}}{1+\delta+\delta^{2}}
$$

in which its derivation can be found in Appendix A (Proof of Proposition 2).

Definition 1. "Expensive" and "highly expensive" divorce equilibria are defined by $\left(\widetilde{\theta}_{e}, \widehat{\theta}_{e}\right)$, where the former exists for $\delta c \in\left(\Phi_{4}, \frac{\delta \widehat{\theta}}{1+\delta}\right)$, and the latter exists for $\delta c>\frac{\delta \widehat{\theta}}{1+\delta}$.

The expensive or the highly expensive divorce equilibria occur when the "divorce option" condition does not hold for non-eligible individuals. Hence, they would rather reject their pretender in $T=1$ than divorce her, because divorce is too expensive. As a consequence, $\Phi_{2}$ is not a relevant threshold anymore: In period 1, they either reject the pretender or marry her with the idea of staying married. In particular, they reject the pretender in $T=1$ if the following is the case.

$$
\left(1+\delta+\delta^{2}\right) \theta_{p 1}<\delta^{2} \widehat{\theta} \Leftrightarrow \theta_{p 1}<\Phi_{4}
$$

Conversely, the behaviour of eligible individuals remains the same as in the baseline model. 
Proposition 5. Suppose $\delta c>\Phi_{2}$. Then, a non-eligible individual performs the following:

- Marries for life in $T=1$ if $\theta_{p 1}>\Phi_{4}$;

- $\quad$ Rejects the match in $T=1$ if $\theta_{p 1}<\Phi_{4}$.

Figure 4 shows the two configurations. These may be relevant particularly when the cost of divorce is hardly bearable for some social groups.

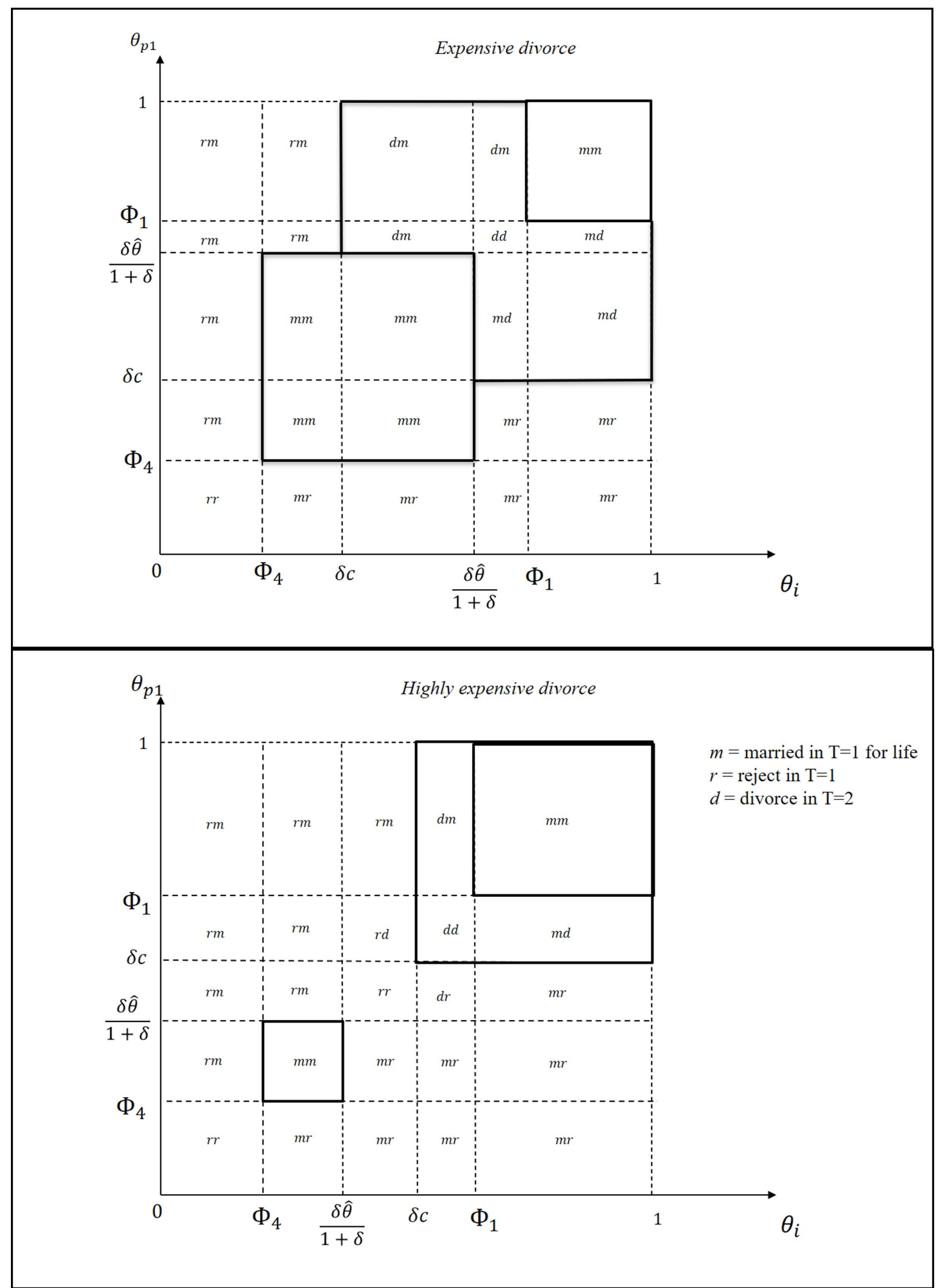

Figure 4. Equilibrium configurations where the divorce option condition does not hold for some individuals. 


\subsection{Assortative Matching and Disconnected Equilibria}

There are two main findings that are robust to all equilibrium configurations. The first regards the implications of endogenous divorce on positive assortative matching. In equilibrium, positive assortative matching emerges when only similar individuals marry each other: individuals agree to marry only with potential partners of the same "block".

However, block segregation is a pathological result for two reasons: First, it yields a equilibrium with discontinuity in a model where types are heterogeneous in a continuum, and (ii) it does not match empirical regularities [32]. While block segregation is a popular finding of the matching literature under non-transferable utility, Smith [32] has shown that block segregation occurs when mutliplicatively separable payoff functions are assumed, and this is because individuals with equal match offerings make identical decisions.

In our framework, positive assortative matching dissolves with divorce for some intermediate types: in Figures 3 and 4, agents from block $r r$ remain single in $T=1$, while agents from block $d d$ divorce their partner in $T=2$. In addition, the fact that the average quality of singles decreases over time implies that the "block" of positive assortative matching becomes larger in $T=2$. This, in turn, implies that types who marry in $T=2$ are more asymmetric than in $T=1$. Therefore, the endogenous positive assortative matching that usually emerges in models with nontransferable utility is weakened when matches can dissolve.

The second finding, related to the first, is that the existence of ranges where divorce occurs among individuals with positive assortative matching entails the existence of two disconnected classes of types: a highest class and an intermediate class. Only upon meeting within one's class do permanent marriages arise. If, during the first period, matchings were to occur with individuals that do not belong to the same class, such a match would be dissolved with divorce at a later stage.

\subsection{Existence of Divorce Equilibria}

In this section, we analyse the conditions for the existence of divorce equilibria. Existence requires the ranking of each equilibrium configuration to hold. Following Remark 1 and Definition 1, the range of existence is where the rank of each divorce type applies for the following:

- Cheap divorce, $\left(\widetilde{\theta}_{d}, \widehat{\theta}_{d}\right)$ with $\Phi_{1}\left(\widetilde{\theta}_{d}\right)>\frac{\delta \widehat{\theta}_{d}}{1+\delta}>\Phi_{2}\left(\widehat{\theta}_{d}\right)>\delta c$;

- $\quad$ Expensive divorce, $\left(\widetilde{\theta}_{e}, \widehat{\theta}_{e}\right)$ with $\Phi_{1}\left(\widetilde{\theta}_{e}\right)>\frac{\delta \widehat{\theta}_{e}}{1+\delta}>\delta c>\Phi_{4}\left(\widehat{\theta}_{e}\right)$;

- Highly expensive divorce, $\left(\widetilde{\theta}_{e}, \widehat{\theta}_{e}\right)$ with $\Phi_{1}\left(\widetilde{\theta}_{e}\right)>\delta c>\frac{\delta \widehat{\theta}_{e}}{1+\delta}>\Phi_{4}\left(\widehat{\theta}_{e}\right)$.

Unfortunately, it is not possible to determine the existence of divorce equilibria analytically. We can, however, evaluate the existence for some values of $(\delta, c)$. To fix ideas, we consider the following values of $\delta: 0.001,0.25,0.5,0.75$ and 0.99 . Figure 5 shows the existence conditions of the baseline results with respect to $c$, while Figures 6 and 7 show the existence conditions of expensive and highly expensive divorce equilibria. The grey, dotted, thick, dashed and black lines are $\Phi_{1}, \frac{\delta \widehat{\theta}}{1+\delta}, \Phi_{2}, \delta c$ and $\Phi_{4}$, respectively.

The results in Figures 5-7 are summarised in Table 2. Some remarks can be drawn from the analysis of existence. In the baseline case, divorce does not emerge when the cost of waiting is very high (very low $\delta$ ). Indeed, the risk of divorcing and ending up, in $T=2$, with a partner that is worse than the divorced one is very high. If $\delta$ is low, there is a stronger incentive in agreeing to match a partner in $T=2$; hence, this risk of "downgrading" increases with lower $\delta$.

Each equilibrium configuration is unique in its range of existence. Consistent with the assumptions, a highly expensive divorce equilibrium emerges when the divorce cost is the highest cost admissible, followed by the expensive divorce equilibrium and the cheap divorce equilibrium. 

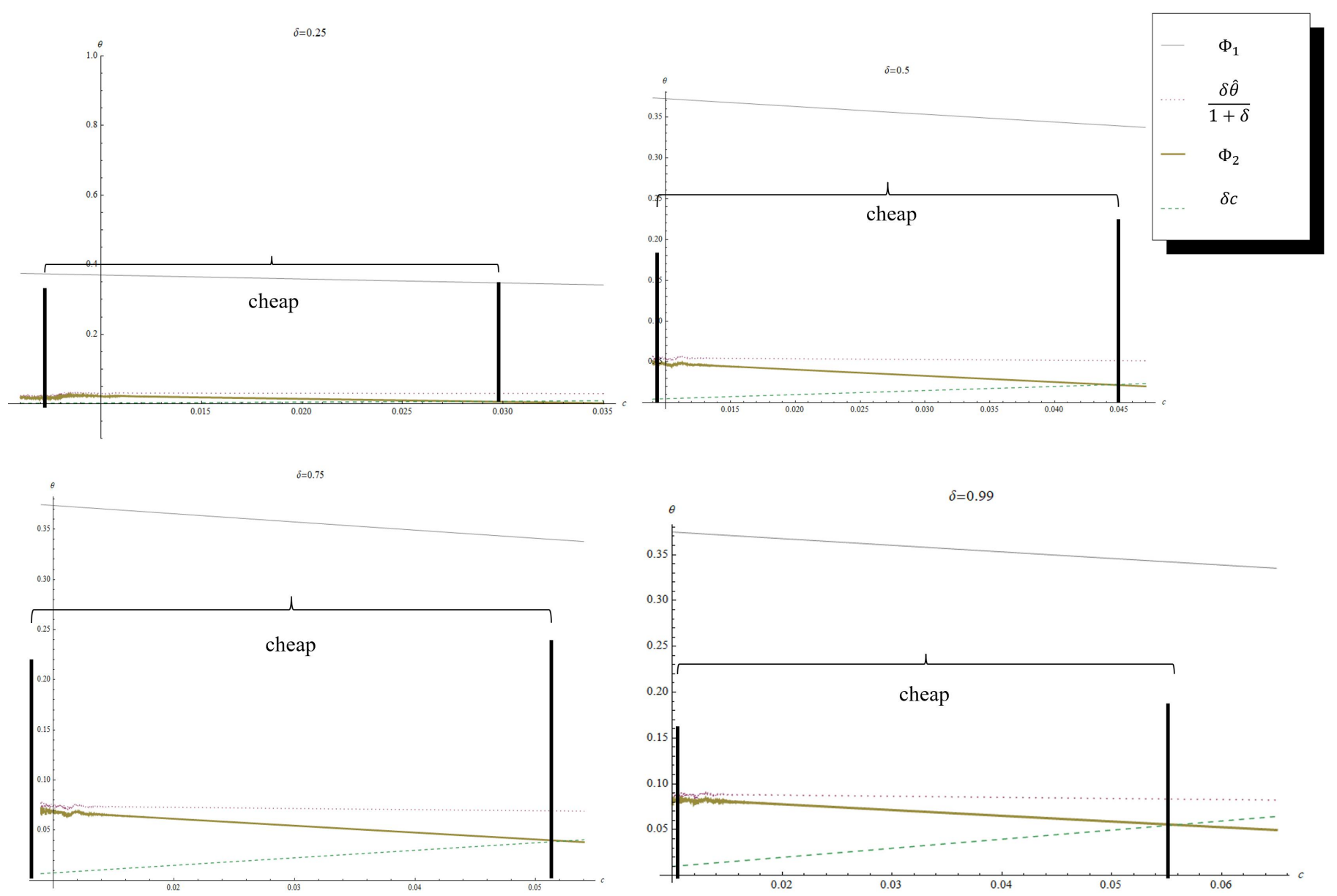

Figure 5. Existence of baseline equilibrium.

Finally, we may discuss the more subtle case where the asymmetry of types occurs between women and men. Suppose that the cost of divorce is for some reason higher for women than men. For example, divorced women used to be socially stigmatised in past societies; in the marriage choice, men appoint a higher value to beauty compared to women [42] such that a loss in attractiveness due to ageing is relatively more harmful for women. We can model this asymmetry as an extra cost that women have to pay in event of a divorce. Although tractability prevents us from eliciting analytical results, we may still propose some reasonable hypotheses. First, equilibria with differing divorce type may emerge between women and men. For example, equilibria may occur where divorce is expensive or highly expensive for women but not for men.

Table 2. Existence conditions.

\begin{tabular}{cccc}
\hline$\delta$ & Cheap & Expensive & High Exp \\
\hline 0.01 & $/$ & $c \lesssim 0.1$ & $0.1 \lesssim c \lesssim 0.25$ \\
0.25 & $0.006 \lesssim c \lesssim 0.03$ & $0.03 \lesssim c \lesssim 0.098$ & $0.098 \lesssim c \lesssim 0.26$ \\
0.5 & $0.01 \lesssim c \lesssim 0.045$ & $0.045 \lesssim 0.09$ & $0.09 \lesssim c \lesssim 0.252$ \\
0.75 & $0.01 \lesssim c \lesssim 0.051$ & $0.051 \lesssim c \lesssim 0.087$ & $0.087 \lesssim c \lesssim 0.239$ \\
0.99 & $0.01 \lesssim c \lesssim 0.056$ & $0.056 \lesssim c \lesssim 0.08$ & $0.08 \lesssim c \lesssim 0.22$ \\
\hline
\end{tabular}




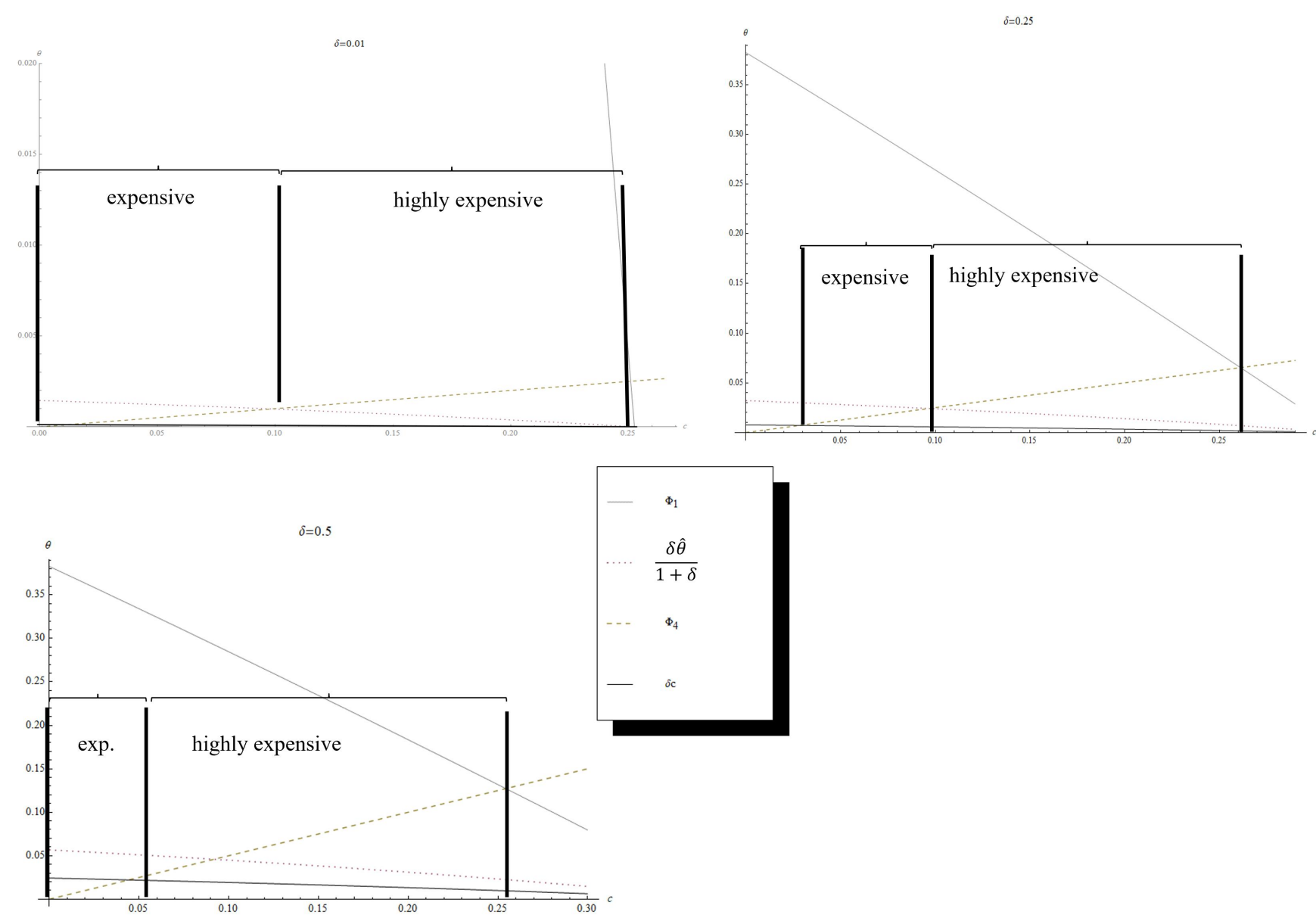

Figure 6. Existence of of expensive and highly expensive equilibria: $\delta=0.01, \delta=0.25$ and $\delta=0.5$.
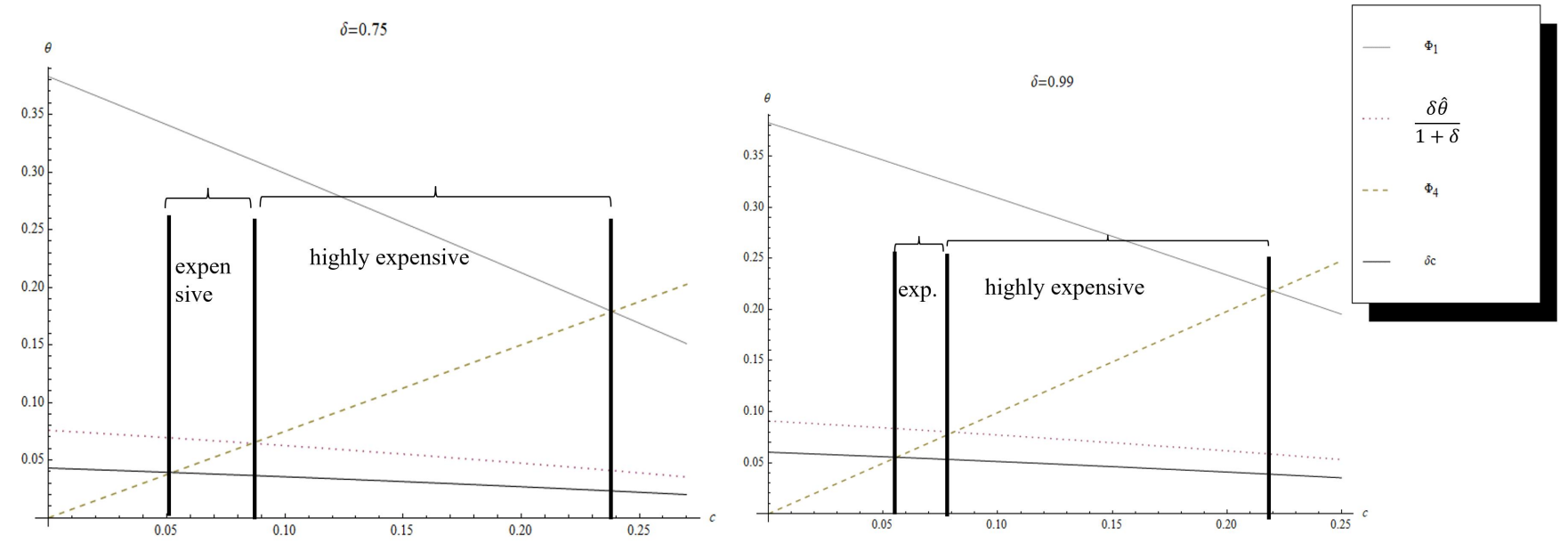

Figure 7. Existence of of expensive and highly expensive equilibria: $\delta=0.75$ and $\delta=0.99$.

\section{Younger Singles}

A possible critique of the analysis so far is that it does not take into account the interaction among partners of different age. In fact, evidence shows that men tend to remarry younger partners $[19,20]$, suggesting that the presence of younger singles should increase the probability of divorce. In this section, we try to capture this effect by considering the entry of a younger generation in the marriage market. 
This variation requires simplifying the setting by restricting the analysis on a twoperiods model. Nothing changes in the first period. In the second period, divorce may still occur, but single and divorced individuals are now randomly matched with mandatory acceptance, and the game ends. Compared to the three-periods model, the following effects are observed:

- Individuals only choose to reject/marry in $T=1$ and to proceed with divorce in $T=2$ if previously married;

- $\quad$ Eligibility in $T=2$ does not play any role.

We denote the expected quality of singles in $T=2$ as $\widetilde{\theta}_{2 T}$. The following proposition provides a new condition for a divorce equilibrium.

Proposition 6. For $c<\frac{\widetilde{\theta}_{2 T}}{1+\delta}$, an individual may choose to proceed with divorce.

Proof. In order for a divorce to occur, two conditions need to take place.

$$
\begin{aligned}
(1+\delta) \theta_{p 1}<\theta_{p 1}+\delta\left(\widetilde{\theta}_{2 T}-c\right) & \Leftrightarrow \theta_{p 1}<\left(\widetilde{\theta}_{2 T}-c\right), \text { unhappiness } \\
\theta_{p 1}+\delta\left(\widetilde{\theta}_{2 T}-c\right)>\delta \widetilde{\theta}_{2 T} & \Leftrightarrow \theta_{p 1}>\delta c, \text { divorce option }
\end{aligned}
$$

This range exists for the following.

$$
\delta c<\widetilde{\theta}_{2 T}-c \Leftrightarrow c<\frac{\widetilde{\theta}_{2 T}}{1+\delta} .
$$

Given Proposition 6, we are able to determine the individuals' behaviour.

Proposition 7. Suppose $c<\frac{\widetilde{\theta}_{2 T}}{1+\delta}$. An individual performs the following:

- Marries for life in $T=1$ if $\theta_{p 1}>\widetilde{\theta}_{2 T}-c$,

- Divorces in $T=2$ if $\theta_{p 1} \in\left(\delta c, \widetilde{\theta}_{2 T}-c\right)$

- $\quad$ Rejects the match in $T=1$ if $\theta_{p 1}<\delta c$.

In this simplified scenario, we compare this case, where only one generation is present in the marriage market, with the case where, at $T=2$, a new generation enters the market in which its members are on their first period of life. The focus of the problem is only the generation at time $T=2$ (the "old" one), whose members take into account the presence of younger singles in their divorce choice. This exercise will allow us to determine the effects of the presence of the younger generation on the features of the divorce equilibrium and in particular if, as the evidence suggests, the presence of younger singles increases the chance of divorce.

The new timing is depicted in Figure 8. Consider first the benchmark case without younger singles: the expected quality of singles in $T=2$ (refer to Appendix D for details) amounts to the following:

$$
\widetilde{\theta}_{2 T}=\frac{3-\sqrt{5+4 c+4 c^{2}}}{2} .
$$

Next, consider the presence of the younger generation in the marriage market: since these individuals just entered the marriage market, the quality of a pretender, given uniform distribution over $[0,1]$, is $\frac{1}{2}$. In addition, to keep things as most neutral as possible, we 
assume that the probability of meeting one pretender of each generation is $\frac{1}{2}$. It follows that the expected quality of singles in $T=2$ is defined as follows:

$$
\widetilde{\theta}_{\text {over }} \equiv \frac{1}{2} \widetilde{\theta}_{2 T}+\frac{1}{2} \frac{1}{2} .
$$

When comparing the two configurations, it is important to remember that, ceteris paribus, a higher expectation of the quality of singles implies a higher probability that divorce will occur. This effect is natural as a higher quality of singles provides an incentive to break up the current marriage. Thus, the presence of younger singles increases the probability of divorce if and only if $\widetilde{\theta}_{2 T}-\widetilde{\theta}_{\text {over }}<0$. This inequality always holds since the following is the case.

$$
\begin{aligned}
\widetilde{\theta}_{2 T}-\left(\frac{1}{2} \widetilde{\theta}_{2 T}+\frac{1}{4}\right) & <0 \Leftrightarrow \\
3-\sqrt{5+4 c+4 c^{2}}-1 & <0 \Leftrightarrow \\
(1+2 c)^{2} & >0 .
\end{aligned}
$$

Thus, Proposition 8 follows.

Proposition 8. Suppose $c<\frac{\widetilde{\theta}_{2 T}}{1+\delta}$. The presence of a younger generation entering the marriage market entails an increase in the probability of divorce.

The result of Proposition 8 is consistent with the empirical evidence that the presence of younger singles increases the probability of divorce. In the model, this result emerges because the average quality of the new generation is higher, because high-quality individuals who are matched to each other in $T=1$ decrease the average quality of the older generation and tend to stay married in $T=2$.

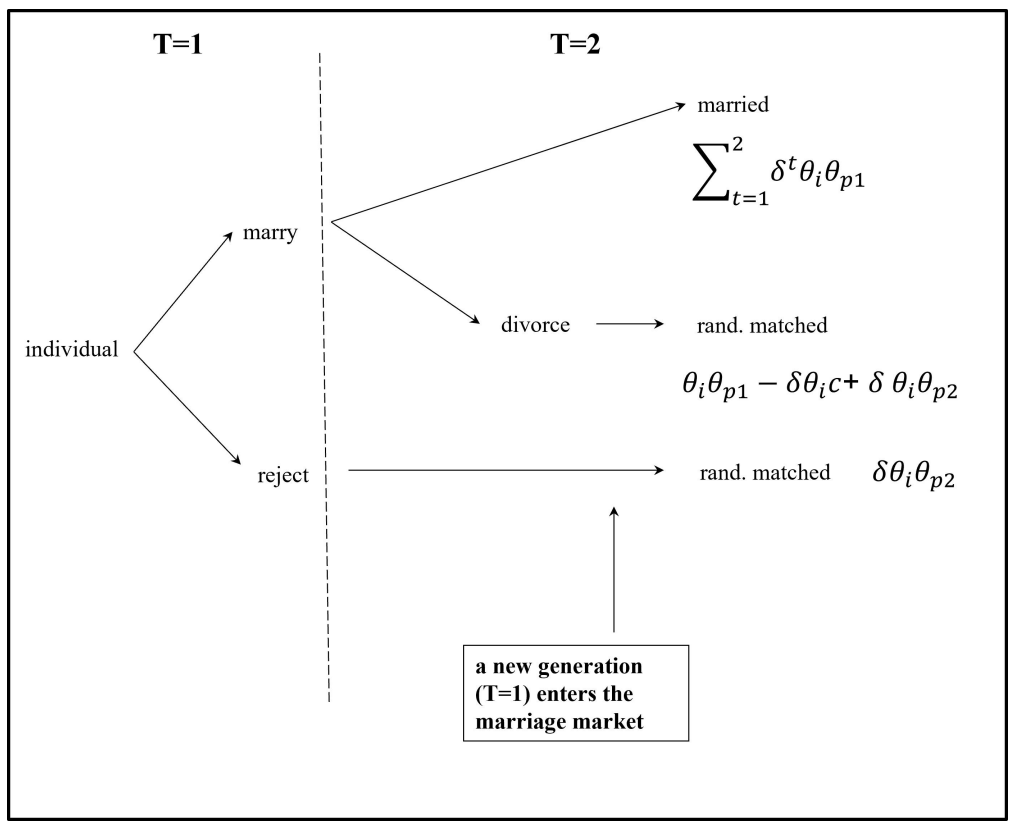

Figure 8. Timing and total utilities in a 2-periods game with one younger generation entering the market.

\section{Empirical Validation}

In this section, we motivate the empirical relevance of our theoretical analysis by using a simple exercise. In particular, we determine which couples divorce according to spouses' characteristics. To perform this examination, we use data from the Marital Instability Over the Life Course study [43]. This dataset is a 20-year panel survey of a 
nationally representative sample of married individuals in the United States. The aim of the original study was to investigate which variables may affect divorce. By using telephone interviews, beginning in 1980, researchers have interviewed a sample of 2034 heterosexual married persons younger than 55 years of age. Respondents were then re-interviewed five other times (1983, 1988, 1992, 1997 and 2000) if available.

We have initially considered three possible spouse features: years of schooling, income and self-rated health status. The second and the last measures were discarded because in a large proportion of couples, only one partner was working, showing significant asymmetry in terms of income, and responses to health status were negligible. Thus, we focused on years of schooling.

For years after 1980, we excluded an observation if the individual did not divorce and did not change the years of schooling acquired in the period, since the observation after 1980 would be only a repetition of the same couple in the first interview. However, we maintained observations after 1980 if the divorce occurred, or if one of the spouses acquired further education. Indeed, the new level of education changes the spouse's characteristic; thus, it is considered a new observation compared to observation of the same couple in 1980 .

In Figure 9, we scatter the years of schooling of respondents and spouses by marking differently whether the couple divorced (thick red cross) or not (black dot). Divorce occurred in the presence of asymmetry among the spouses' years of education or in the case of symmetry if spouses acquired a medium range of years of schooling.

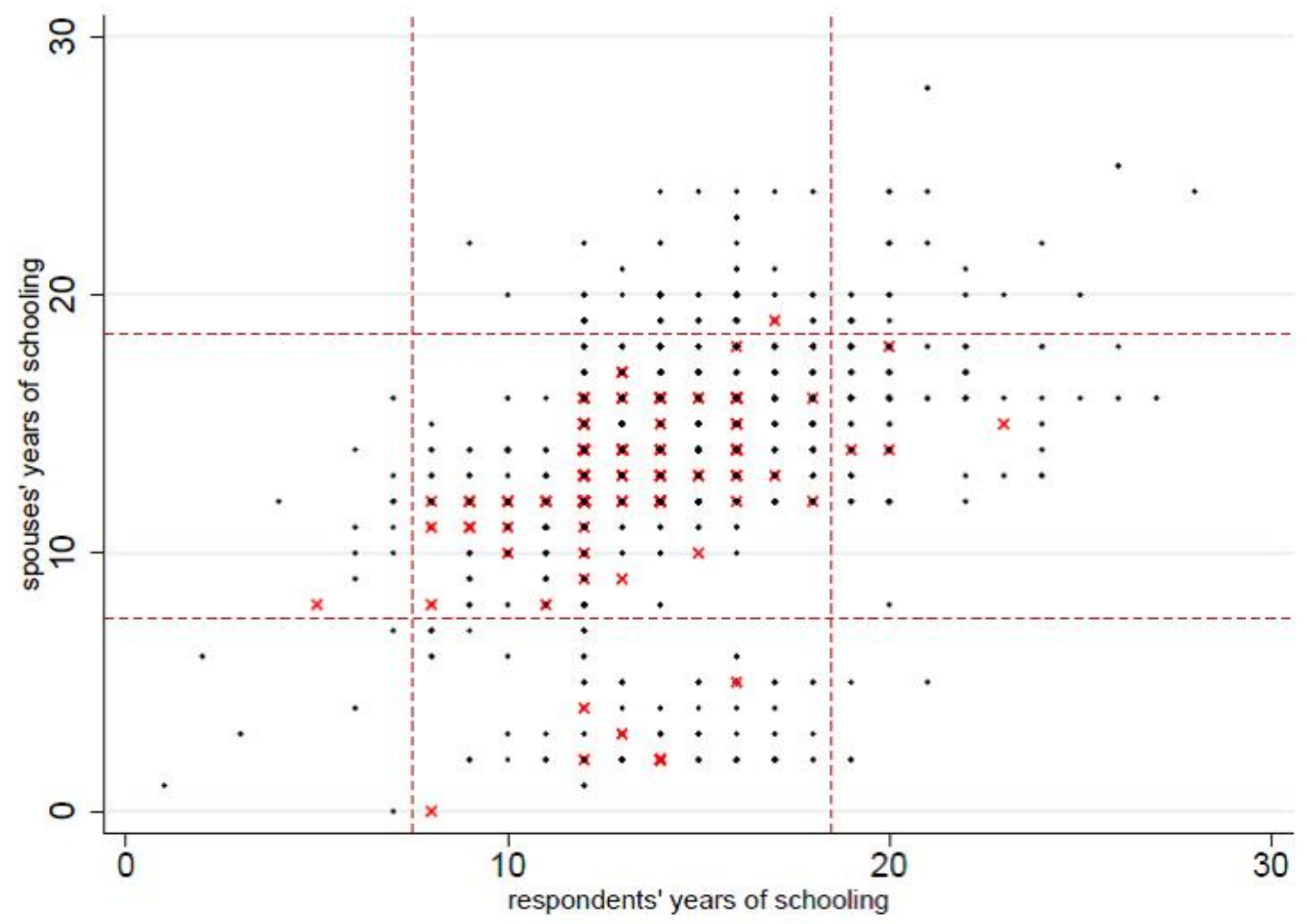

Figure 9. Divorce choice according to spouses' education: red cross = divorced couple; back dot= married couple.

The evidence in Figure 9 seems consistent with the cheap divorce configuration outlined in Figure 3, where spouse types are represented by years of schooling. In particular, divorced couples in the data have medium/symmetric or asymmetric levels of education. Unfortunately, the dataset does not provide any information on rejections, which limits the comparison with the theory. 


\section{Discussion}

\subsection{Relevance for Psychology}

As stated in Section 1, there is strong psychological evidence of the contextual effects on cognitive processing and, in particular, decision making [15-18]. With regard to search and matching behaviours, social psychology has repeatedly observed how individual decisions affect the expected result of a certain outcome for everyone [44-46]. Compared to classical approaches, our model includes more realistic assumptions (i.e., the influence of marital choices on the population of singles, taking into account the quality of singles) in the analysis of marriage markets.

Moreover, the Bayesian approach employed in our model is related to the influential rational analysis framework in psychology [47-49]. The rational analysis approach tries to understand the mind and its behaviour in terms of the problems of the system it solves or overcomes and, similarly, why it performs such processes. Initially, rational analysis has been very successful when applied to basic processes such as perception [50]. At the end of the 1990s, Griffiths and Tenenbaum [51] showed how even high-level cognitive processes (such as reasoning and inductive learning) can be successfully modeled and predicted by using the Bayesian framework. This was a surprising result given the common view that cognitive judgments are typically error-prone and insensitive priors (as testified by the famous heuristic and bias research program by Kahneman and Tversky [52]). This apparent contradiction is explained on the basis of which optimal criterion is taken into account by the cognitive system. With regard to our model, individuals are "Bayesian" (i.e., their decision are optimal according to Bayes' rule) in the sense that they determine the expected quality of singles conditional to the "type" of singles that are present in the market: for instance, singles who previously refused partners, singles who divorced their spouses, singles who were divorced by their spouses and so on. In Section 6, we have provided preliminary empirical evidence in line with the predictions of our theoretical analysis. Overall, our paper may represent a preliminary contribution of a rational analysis approach with respect to searching and matching decision making.

\subsection{Divorce Legislation}

As discussed before, divorce decisions are strictly related with legislation. Recent empirical evidence investigated the impact of divorce legislation on divorce rate [8,9]. Two crucial reforms in divorce law regarded the introduction of unilateral and no-fault divorce. These reforms have been both applied at the end of the 1960s in the United States. In European countries, instead, they have been introduced over the 20th century and are usually introduced separately [53].

No-fault divorce requests can be filed for incompatibility, irreconcilable differences and irretrievable breakdown. No proof of fault is necessary, and it can be completed more quickly than fault divorces. Moreover, no-fault divorce is less costly compared to fault divorces [54]. Hence, in our model, the introduction of a no-fault divorce reform coincides with lowering divorce $\operatorname{costs} c$.

On the contrary, unilateral divorce does not require mutual consent and can be granted at the request of either spouse. The right of unilateral divorce may be exercised even under fault divorce legislation if the spouse is guilty of a grave matrimonial offense, such as physical abuse or adultery (In this case, the applicant must exhibit proof of the fault in court). In our model, unilateral divorce occurs for asymmetric types (outcomes $d m$ or $m d$ in Figure 3), which would be banned if consensual divorce was the only option in divorce legislation. In other terms, without the unilateral divorce option, the only divorced individuals will be those who mutually choose to proceed with divorce (outcomes $d d$ ).

A possible link between the introduction of no-fault and unilateral divorce legislation and the increase in divorce rates has been an object of strong debate over the past decades: Empirical analysis has shown ambiguous evidence of these reforms on divorce rates [55-60]. The general impression is that divorce liberalisation may have resulted in a short-term 
increase in divorce, but it reversed 15 years later due to changes in marriage patterns that responded to this phenomenon [53,61].

Our theoretical results are consistent with empirical evidence in the short term; that is, it seems helpful to represent the immediate effect of reducing divorce costs. Indeed, the introduction of no-fault divorce legislation corresponds to the fall in $c$, which in turn entails a higher probability of divorcing as the equilibrium outcome may shift from highly expensive and expensive to cheap divorce.

\subsection{Generalisation to Other Domains}

In this paper, we have taken into account marriage markets $[23,27,28]$ as a case study of search and matching behaviours. At first hand, our approach may be generalised to similar search and matching contexts such as the labour market. Indeed, our theoretical analysis may be applied to hiring decisions [62]: In this case, hiring a job candidate or accepting a job modifies the expectation about the quality of candidates in the labour market or the quality of employers. There are several other domains where our approach can be extended and adapted. For example, decision making with respect to individual health and related behaviours [63-67] may require certain forms of search and matching behaviours. In some health system, each resident is entitled to choose a general practitioner from a pool of physicians. However, each physician may follow only a limited number of patients, so residents must choose among the best available options in terms of general practitioners. A similar story holds true also for the access to medical tests or treatments in the case of several suitable options that can be ranked in terms of desirability/goodness (and each option can be chosen only by a limited number of people). Such cases can be ideal for finding empirical data to validate the current analysis: Given the spread of internet-connected computer systems (via smartphones, tablets and wearable devices) and information and communication technologies, a vast amount of information about human behaviour (and, in particular, health-related information) is systematically stored in databases [68-71]. Such Big Data approaches might represent a convenient tool for testing our context-sensitive game-based model of search and matching behaviours.

\section{Concluding Remarks}

We have analysed a model of endogenous divorce, in a three-period framework where the population is heterogeneous in quality, and the distribution of singles is affected by marriage choice. We have outlined the conditions for "cheap," "expensive," and "highly expensive" divorce equilibria. Each equilibrium exists, and it is unique in its parameter region. The divorce takes place in the presence of asymmetry among the spouse types or symmetric, medium-type spouses. We have shown that our theory is consistent with a simple empirical exercise, and it fits the effects of the adoption of divorce reforms on divorce choice in the short run.

We have found that, because of divorce, assortative matching disappears for some intermediate types. Moreover, two classes of types emerged: if matchings were to occur with individuals of different classes in the initial period, these would later be dissolved.

Some of the key assumptions of the framework deserve to be discussed. First, the assumption of nontransferable utility. The most appreciated approach by the literature, dating back to Becker [72], is transferable utility. Indeed, in many standard labour models of households, the models employ a "collective model" where utility is fully transferable. The assumption of non-tranferable utility is a polar case that disregards transfers within the match such as, let us say, performing housework or looking after the children.

However, the assumption of non-transferable utility entails disagreements about matching, which seems particularly relevant in the analysis of divorce. More generally, any time that a possible formation of a couple or divorce is sought by one partner only, utility is clearly not fully transferable. In addition, non-tranferable utility implies that an equal share of the household utility is particularly fit nowadays. Indeed, since women entered the work 
force and gained reproductive rights, the division of household duties is becoming more and more equal.

Another key feature of the model is the assumption of random matching. This is less restrictive than, say, assuming some similarities among individuals who match, such as "directed search": Individuals search for someone more is similar to them or meet with potential partners from the same social group, at work or partners that have similar interests in common. However, this assumption brings about some problems: The fact that matching is random provides hope to very low types in that they could be matched with high types in later periods of life, and this delays their matches. This might not occur in real life: in later stages of life, people tend to deal with individuals with similar features, jobs, social class, etc. Hence, it would be admissible to assume directed search for matches in later periods of life, such as $\mathrm{T}=2$ and $\mathrm{T}=3$. At the same time, assuming directed search would prevent showing the effects of positive assortative matching dissolution among intermediate high types, which is something observed in reality.

Author Contributions: Conceptualization, A.T.; Formal analysis, E.P. and A.T.; Writing—original draft preparation, G.G., E.P. and A.T.; Writing—review \& editing, G.G. and A.T. All authors have read and agreed to the published version of the manuscript.

Funding: This research received no external funding.

Institutional Review Board Statement: Not applicable.

Informed Consent Statement: Not applicable.

Data Availability Statement: Not applicable.

Conflicts of Interest: The authors declare no conflict of interest.

\section{Appendix A}

In this appendix, we include a proof of the divorce conditions (Proposition 1) as well as the proofs of the equilibrium strategy of eligible and non-eligible individuals (Proposition 2 and Proposition 3).

\section{Appendix A.1. Proof of Proposition 1}

Consider first $\theta_{i}>\frac{\delta \widehat{\theta}}{1+\delta}$. In order for divorce to occur, two conditions need to take place.

$$
\begin{gathered}
\left(1+\delta+\delta^{2}\right) \theta_{p 1}<\max \left\{\theta_{p 1}-\delta c+\delta(1+\delta) \widetilde{\theta}, \theta_{p 1}-\delta c+\delta^{2} \widehat{\theta}\right\}, \\
\Leftrightarrow \theta_{p 1}<\max \left\{\widetilde{\theta}, \frac{\delta \widehat{\theta}}{1+\delta}\right\}-\frac{c}{1+\delta^{\prime}}, \text { (unhappiness) } \\
\theta_{p}-\delta c+\delta(1+\delta) \widetilde{\theta}>\delta(1+\delta) \widetilde{\theta} \Leftrightarrow \theta_{p}>\delta c \text {, (divorce option) }
\end{gathered}
$$

These two conditions may be verified if the following is the case.

$$
\begin{aligned}
& \max \left\{\widetilde{\theta}, \frac{\delta \widehat{\theta}}{1+\delta}\right\}-\frac{c}{1+\delta}>\delta c \\
& \Leftrightarrow c<\frac{(1+\delta) \max \left\{\widetilde{\theta}, \frac{\delta \widehat{\theta}}{1+\delta}\right\}}{1+\delta+\delta^{2}} .
\end{aligned}
$$

Consider $\theta_{i}<\frac{\delta \widehat{\theta}}{1+\delta}$ next. In order for divorce to occur, the two conditions must be satisfied.

$$
\left(1+\delta+\delta^{2}\right) \theta_{p 1}<\theta_{p 1}-\delta c+\delta^{2} \widehat{\theta}
$$




$$
\begin{gathered}
\Leftrightarrow \theta_{p 1}<\frac{\delta \widehat{\theta}-c}{1+\delta}, \text { unhappiness } \\
\theta_{p}-\delta c+\delta^{2} \widehat{\theta}>\delta^{2} \widehat{\theta} \Rightarrow \theta_{p}>\delta c \text { divorce option }
\end{gathered}
$$

These two conditions hold if the following is the case.

$$
\frac{\delta \widehat{\theta}-c}{1+\delta}>\delta c \Rightarrow c<\frac{\delta \widehat{\theta}}{1+\delta+\delta^{2}} .
$$

Appendix A.2. Proof of Proposition 2

If $\widetilde{\theta}>\frac{\delta \hat{\theta}}{1+\delta}$, individual $i$ expects, after divorce, to marry in $T=2$; thus, he divorces if $\theta_{p 1}<\Phi_{1}$. If $\widetilde{\theta}>\frac{\delta \widehat{\theta}}{1+\delta}$, individual $i$ expects, after divorce, to marry in $T=3$; thus, he divorces if $\theta_{p 1}<\Phi_{2}$.

Returning to $T=1$, if $\widetilde{\theta}>\frac{\delta \widehat{\theta}}{1+\delta}$, he will choose between marrying and rejecting for $\theta_{p 1} \geq \Phi_{1}$ and between divorcing and rejecting for $\theta_{p 1}<\Phi_{1}$. If $\theta_{p 1} \geq \Phi_{1}$, individual $i$ prefers to reject the pretender in $T=1$ if the following is the case:

$$
\left(1+\delta+\delta^{2}\right) \theta_{p 1}<\delta(1+\delta) \widetilde{\theta}
$$

for the following case.

$$
\theta_{p 1}<\frac{(1+\delta) \delta \widetilde{\theta}}{1+\delta+\delta^{2}} \equiv \Phi_{3}
$$

Notice that the following obtains.

$$
\begin{gathered}
\Phi_{1}>\Phi_{3} \Leftrightarrow \\
\widetilde{\theta}-\frac{c}{1+\delta}>\frac{(1+\delta) \delta \widetilde{\theta}}{1+\delta+\delta^{2}} \text { for } c<\frac{(1+\delta) \widetilde{\theta}}{1+\delta+\delta^{2}} .
\end{gathered}
$$

Therefore, whenever a divorce may occur by Proposition 1 , threshold $\Phi_{3}$ is not binding whenever $\theta_{p 1}>\Phi_{1}$.

If $\theta_{p 1}<\Phi_{1}$, individual $i$ prefers to reject the pretender in $T=1$ if the following is the case:

$$
\theta_{p 1}-\delta c+\delta(1+\delta) \widetilde{\theta}<\delta(1+\delta) \widetilde{\theta}
$$

for $\theta_{p 1}<\delta c$.

If $\frac{\delta \widehat{\theta}}{1+\delta}>\widetilde{\theta}$ and $\theta_{p 1} \geq \Phi_{2}$, individual $i$ prefers to reject the pretender in $T=1$ if the following is the case:

$$
\left(1+\delta+\delta^{2}\right) \theta_{p 1}<\delta^{2} \widehat{\theta}
$$

for the following.

$$
\theta_{p 1}<\frac{\delta^{2} \widehat{\theta}}{1+\delta+\delta^{2}} \equiv \Phi_{4}
$$

Notice that the following is obtained.

$$
\begin{gathered}
\Phi_{2}>\Phi_{4} \Leftrightarrow \\
\frac{\delta \widehat{\theta}-c}{1+\delta}>\frac{\delta^{2} \widehat{\theta}}{1+\delta+\delta^{2}} \text { for } c<\frac{\delta \widehat{\theta}}{1+\delta+\delta^{2}} .
\end{gathered}
$$

Hence, everytime a divorce may occur by Proposition 1, threshold $\Phi_{4}$ is not binding whenever $\theta_{p 1}>\Phi_{1}$. If $\theta_{p 1}<\Phi_{2}$, individual $i$ prefers to reject the pretender in $T=1$ if the following is the case.

$$
\theta_{p 1}-\delta c+\delta^{2} \widehat{\theta}<\delta^{2} \widehat{\theta} \Leftrightarrow \theta_{p 1}>\delta c .
$$




\section{Appendix A.3. Proof of Proposition 3}

A non-eligible individual expects to be rejected in $T=2$ but still might want to divorce his partner if the expected payoff of $T=3$ is sufficiently high. Following previous comparisons, this occurs if $\theta_{p 1}<\Phi_{2}$.

Returning to $T=1$, individual $i$ will choose between marrying and rejecting for $\theta_{p 1}>\Phi_{2}$ and between divorcing and rejecting for $\theta_{p 1}<\Phi_{2}$ and for $\theta_{p 1}>\Phi_{2}$.

$$
\left(1+\delta+\delta^{2}\right) \theta_{p 1}<\delta^{2} \widehat{\theta}, \text { if } \theta_{p 1}<\Phi_{4}
$$

By Proposition 1, the conditions of a divorce equilibrium imply $\Phi_{2}>\Phi_{4}$. It follows that this threshold is not binding whenever $\theta_{p 1}>\Phi_{2}$, and individual $i$ always chooses to marry in this case. Consider $\theta_{p 1}<\Phi_{2}$ next.

$$
\theta_{p 1}-\delta c+\delta^{2} \widehat{\theta}<\delta^{2} \widehat{\theta}, \text { if } \theta_{p 1}<\delta c .
$$

\section{Appendix B. Proof of Proposition 4}

We prove the proposition by contradiction. Suppose instead that $\frac{\delta \widehat{\theta}}{1+\delta}>\Phi_{1}$. In order to verify this, we need to split the proof in two parts: one where we assume that $\frac{\delta \hat{\theta}}{1+\delta}>\widetilde{\theta}$ and the other where we assume that $\frac{\delta \widehat{\theta}}{1+\delta} \in\left(\Phi_{1}, \widetilde{\theta}\right)$. This procedure is necessary because, since $\widetilde{\theta}$ and $\widehat{\theta}$ are endogenous, their values change according to each equilibrium configuration.

Appendix B.1. Case 1: $\frac{\delta \widehat{\theta}}{1+\delta}>\widetilde{\theta}$

First, we need to find the values of $\widetilde{\theta}$ and $\widehat{\theta}$ for the equilibrium configuration where $\frac{\delta \hat{\theta}}{1+\delta}>\widetilde{\theta}$. To perform this, we use the results of Propositions 2 and 3 from which we can infer which of the individuals are single in $T=2$ and $T=3$, respectively. Figure A1 helps to explain the situation. It shows the marriage choices in $T=1$ and the divorce choices in $T=2$. In every region, each letter represents the behaviour of agents $i$ and $p 1$, with the first letter indicating the partner's behaviour and the second letter indicating the individual's behaviour. Marriage takes place in $T=1$ and lasts for the entire game if both letters are $m$ (married), $r$ indicates that one agent rejects the person met in $T=1$ and, finally, $d$ indicates that one divorces in $T=2$. Thus, for example, an individual $i$ of type $\theta_{i}>\frac{\delta \widehat{\theta}}{1+\delta}$ agrees to marry a potential partner of type $\theta_{p 1}>\frac{\delta \widehat{\theta}}{1+\delta}$, and he is reciprocated (letters $m m$ ) but divorces type $\theta_{p 1} \in\left(\delta c, \frac{\delta \widehat{\theta}}{1+\delta}-\frac{c}{1+\delta}\right)$, who instead would be happy to remain married (letters $m d$ ).

As a consequence, all matching combinations that did not provide an $\mathrm{mm}$ split in $T=2$. Remember that we are focusing only on one side, (individuals instead of pretenders); thus, we are interested only on the proportion of single pretenders (of course, the same applies in the other side of the market). Hence, single pretenders in $T=2$ are described as follows:

- $\quad$ Eligibles $\theta_{p 1} \in\left(\frac{\delta \hat{\theta}}{1+\delta}, 1\right)$, who met individuals $\theta_{i} \in\left(0, \frac{\delta \widehat{\theta}}{1+\delta}-\frac{c}{1+\delta}\right)$, with probability $\left(1-\frac{\delta \widehat{\theta}}{1+\delta}\right)\left(\frac{\delta \widehat{\theta}}{1+\delta}-\frac{c}{1+\delta}\right)$ who yield an expected payoff of $\frac{\frac{\delta \widehat{\theta}}{1+\delta}+1}{2}$;

- Non-eligibles of type $\theta_{p 1} \in\left(\frac{\delta \widehat{\theta}}{1+\delta}-\frac{c}{1+\delta}, \frac{\delta \widehat{\theta}}{1+\delta}\right)$, who met individuals $\theta_{i} \in\left(0, \frac{\delta \widehat{\theta}}{1+\delta}-\frac{c}{1+\delta}\right)$, with probability $\frac{c}{1+\delta}\left(\frac{\delta \widehat{\theta}}{1+\delta}-\frac{c}{1+\delta}\right)$ who yield an expected payoff of $\frac{2 \frac{\delta \widehat{\theta}}{1+\delta}-\frac{c}{1+\delta}}{2}$;

- $\quad$ non-eligibles of type $\theta_{p 1} \in\left(0, \frac{\delta \widehat{\theta}}{1+\delta}-\frac{c}{1+\delta}\right)$, who met individuals $\theta_{i} \in(0,1)$, with probability $\left(\frac{\delta \widehat{\theta}}{1+\delta}-\frac{c}{1+\delta}\right)$ who yield an expected payoff of $\frac{\frac{\delta \hat{\theta}}{1+\delta}-\frac{c}{1+\delta}}{2}$. 


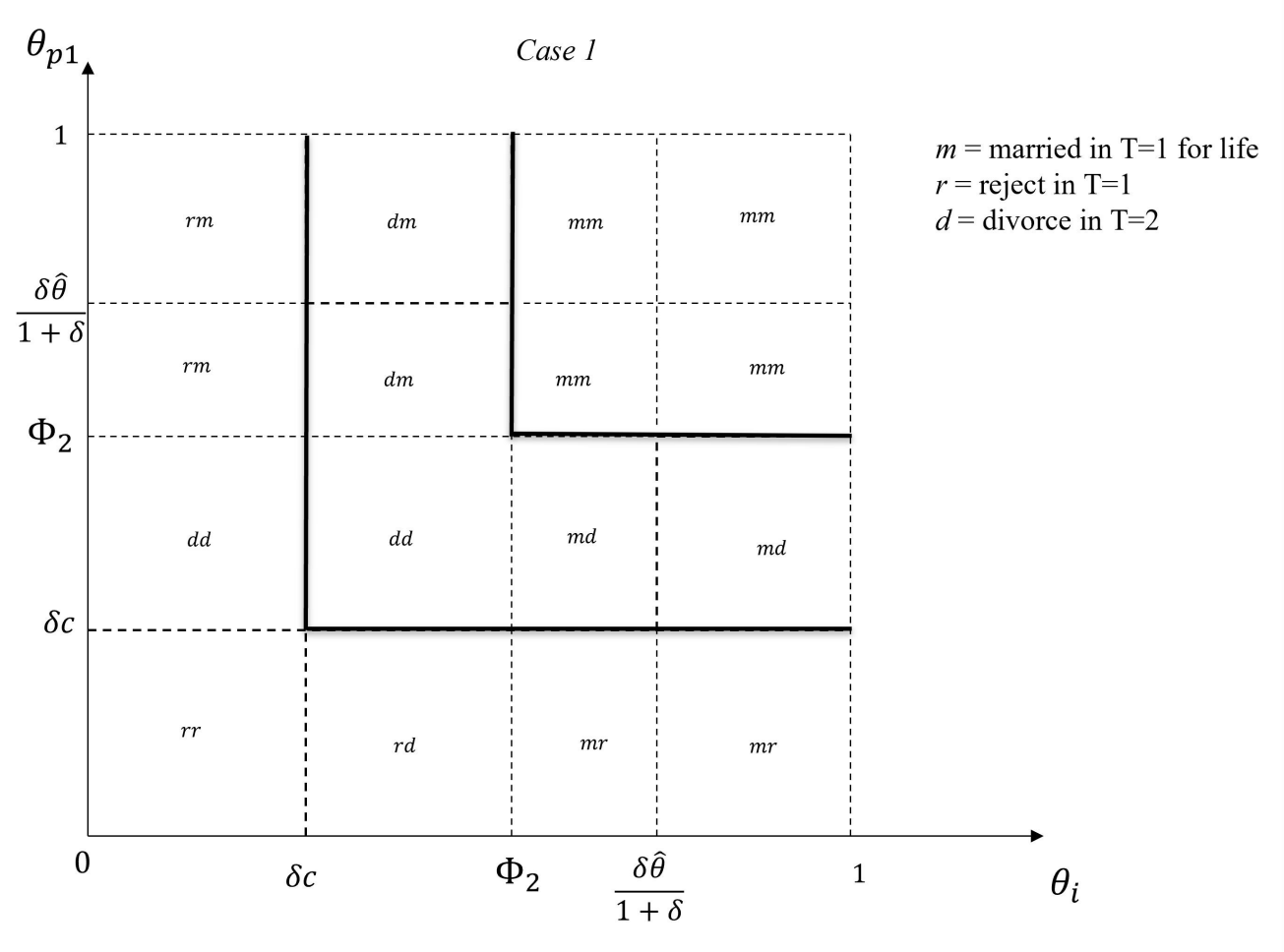

Figure A1. Equilibrium configuration for $\frac{\delta \widehat{\theta}}{1+\delta}>\widetilde{\theta}$.

By using Bayes' rule and performing simplification, the expected quality in $T=2$ is provided by the following.

$$
\widetilde{\theta}=\frac{\left(1-\frac{\delta \widehat{\theta}}{1+\delta}\right) \frac{\frac{\delta \widehat{\theta}}{1+\delta}+1}{2}+\frac{c}{1+\delta} \frac{2 \frac{\delta \hat{\theta}}{1+\delta}-\frac{c}{1+\delta}}{2}+\frac{\frac{\delta \widehat{\theta}}{1+\delta}-\frac{c}{1+\delta}}{2}}{\left(1-\frac{\delta \widehat{\theta}}{1+\delta}\right)+\frac{c}{1+\delta}+1} .
$$

In $T=3$, single pretenders are single in $T=2$ of type $>\frac{\delta \widehat{\theta}}{1+\delta}$, who met someone of a type lower than $\frac{\delta \hat{\theta}}{1+\delta}$ or pretenders of type $<\frac{\delta \widehat{\theta}}{1+\delta}$ who, necessarily, are rejected in $T=2$; thus, they move forward to $T=3$ as singles with probability one. The following, thus, results.

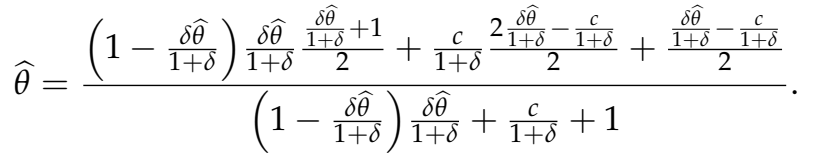

We are now in a position to evaluate whether $\widetilde{\theta}>\frac{\delta}{1+\delta} \widehat{\theta}$, which would produce a contradiction. In order to ease the exposition, we temporarily define the following.

$$
\begin{aligned}
& A_{1}=\left(1-\frac{\delta \widehat{\theta}}{1+\delta}\right) \frac{\frac{\delta \hat{\theta}}{1+\delta}+1}{2} \\
& B_{1}=\frac{c}{1+\delta} \frac{2 \frac{\delta \hat{\theta}}{1+\delta}-\frac{c}{1+\delta}}{2}+\frac{\frac{\delta \hat{\theta}}{1+\delta}-\frac{c}{1+\delta}}{2} \text {; } \\
& C_{1}=\left(1-\frac{\delta \widehat{\theta}}{1+\delta}\right) \text {; } \\
& D_{1}=\frac{c}{1+\delta}+1 \text {. }
\end{aligned}
$$


In this manner, we can rewrite the following.

$$
\widetilde{\theta}=\frac{A_{1}+B_{1}}{C_{1}+D_{1}} \text { and } \widehat{\theta}=\frac{\frac{\delta \widehat{\theta}}{1+\delta} A_{1}+B_{1}}{\frac{\delta \widehat{\theta}}{1+\delta} C_{1}+D_{1}} .
$$

We want to verify if the following is the case:

$$
\frac{A_{1}+B_{1}}{C_{1}+D_{1}}>\frac{\delta}{1+\delta} \frac{\frac{\delta \widehat{\theta}}{1+\delta} A_{1}+B_{1}}{\frac{\delta \widehat{\theta}}{1+\delta} C_{1}+D_{1}} .
$$

which can be rewritten as follows.

$$
\frac{A_{1}+B_{1}}{C_{1}+D_{1}}>\frac{\delta}{1+\delta} \frac{\delta \widehat{\theta} A_{1}+(1+\delta) B_{1}}{\delta \widehat{\theta} C_{1}+(1+\delta) D_{1}}
$$

The above can be rearranged into the following form.

$$
\frac{A_{1}+B_{1}}{C_{1}+D_{1}}>\frac{\frac{\delta \widehat{\theta}}{1+\delta} A_{1}+B_{1}}{\frac{\delta \widehat{\theta}}{\delta} C_{1}+\frac{(1+\delta)}{\delta} D_{1}} .
$$

A quick glance shows that the numerator of the LHS is always higher than the numerator of the RHS. This relationship is, thus, verified if the denominator of RHS is higher than that of the LHS. In other words, we have the following.

$$
C_{1}<\widehat{\theta} C_{1}+\frac{1}{\delta} D_{1} \Leftrightarrow \delta C_{1}(1-\widehat{\theta})<D_{1} .
$$

By using the values of $C_{1}$ and $D_{1}$, we obtain the following.

$$
\delta(1-\widehat{\theta})\left(1-\frac{\delta \widehat{\theta}}{1+\delta}\right)<\frac{c}{1+\delta}+1
$$

The LHS is smaller than one; thus, the sign of the inequality is always verified.

Proposition 1 ensures that this relationship is true, $\widetilde{\theta}>\frac{\delta \widehat{\theta}}{1+\delta}$. However, this contradicts the initial assumption of the equilibrium configuration.

Appendix B.2. Case 2: $\frac{\delta \widehat{\theta}}{1+\delta} \in\left(\widetilde{\theta}-\frac{c}{1+\delta}, \widetilde{\theta}\right)$

Again, we need first to find the values of $\widetilde{\theta}$ and $\widehat{\theta}$ for the equilibrium configuration where $\frac{\delta \hat{\theta}}{1+\delta} \in\left(\widetilde{\theta}-\frac{c}{1+\delta}, \widetilde{\theta}\right)$. To perform this, we use the results of Propositions 2 and 3, from which we can infer which of the individuals are single in $T=2$ and $T=3$, respectively.

Figure A2 shows the equilibrium configuration: single pretenders in $T=2$ are defined as follows:

- $\quad$ Eligibles $\theta_{p 1} \in\left(\frac{\delta \widehat{\theta}}{1+\delta}, 1\right)$ who met individuals $\theta_{i} \in\left(0, \widetilde{\theta}-\frac{c}{1+\delta}\right)$, with probability $\left(1-\frac{\delta \widehat{\theta}}{1+\delta}\right)\left(\widetilde{\theta}-\frac{c}{1+\delta}\right)$ who yield an expected payoff of $\frac{\frac{\delta \hat{\theta}}{1+\delta}+1}{2}$;

- Non-eligibles of type $\theta_{p 1} \in\left(\widetilde{\theta}-\frac{c}{1+\delta}, \frac{\delta \widehat{\theta}}{1+\delta}\right)$ who met individuals $\theta_{i} \in\left(0, \frac{\delta \widehat{\theta}}{1+\delta}-\frac{c}{1+\delta}\right)$, with probability $\left(\frac{\delta \widehat{\theta}}{1+\delta}-\widetilde{\theta}+\frac{c}{1+\delta}\right)\left(\frac{\delta \widehat{\theta}}{1+\delta}-\frac{c}{1+\delta}\right)$ who yield an expected payoff of $\frac{\widetilde{\theta}-\frac{c}{1+\delta}+\frac{\delta \hat{\theta}}{1+\delta}}{2}$;

- Non-eligibles of type $\theta_{p 1} \in\left(\frac{\delta \widehat{\theta}}{1+\delta}-\frac{c}{1+\delta}, \widetilde{\theta}-\frac{c}{1+\delta}\right)$ who met individuals $\theta_{i} \in\left(0, \frac{\delta \widehat{\theta}}{1+\delta}-\frac{c}{1+\delta}\right)$, with probability $\left(\widetilde{\theta}-\frac{\delta \widehat{\theta}}{1+\delta}\right)\left(\frac{\delta \widehat{\theta}}{1+\delta}-\frac{c}{1+\delta}\right)$ or individuals $\theta_{i} \in$ 
$\left(\frac{\delta \widehat{\theta}}{1+\delta}, 1\right)$ with probability $\left(\widetilde{\theta}-\frac{\delta \widehat{\theta}}{1+\delta}\right)\left(1-\frac{\delta \widehat{\theta}}{1+\delta}\right)$ who yield an expected payoff of $\frac{\widetilde{\theta}+\frac{\delta \hat{\theta}}{1+\delta}-2 \frac{c}{1+\delta}}{2}$;

- Non-eligibles of type $\theta_{p 1} \in\left(0, \frac{\delta \widehat{\theta}}{1+\delta}-\frac{c}{1+\delta}\right)$ who met individuals $\theta_{i} \in(0,1)$ with probability $\left(\frac{\delta \widehat{\theta}}{1+\delta}-\frac{c}{1+\delta}\right)$ who yield an expected payoff of $\frac{\frac{\delta \hat{\theta}}{1+\delta}-\frac{c}{1+\delta}}{2}$.

By Bayes' rule, the expected quality in $T=2$ is provided by the following.

$$
\begin{aligned}
& \widetilde{\theta}=\frac{\left(1-\frac{\delta \hat{\theta}}{1+\delta}\right)\left(\widetilde{\theta}-\frac{c}{1+\delta}\right) \frac{\frac{\delta \hat{\theta}}{1++}+1}{2}+\left(\frac{\delta \hat{\theta}}{1+\delta}-\widetilde{\theta}+\frac{c}{1+\delta}\right)\left(\frac{\delta \hat{\theta}}{1+\delta}-\frac{c}{1+\delta}\right) \frac{\tilde{\theta}-\frac{c}{1+\delta}+\frac{\delta \hat{\theta}}{2}}{1+\delta}}{\left(1-\frac{\delta \hat{\theta}}{1+\delta}\right)\left(\widetilde{\theta}-\frac{c}{1+\delta}\right)+\left(\frac{\delta \hat{\theta}}{1+\delta}-\widetilde{\theta}+\frac{c}{1+\delta}\right)\left(\frac{\delta \hat{\theta}}{1+\delta}-\frac{c}{1+\delta}\right)+\left(\widetilde{\theta}-\frac{\delta \hat{\theta}}{1+\delta}\right)\left(1-\frac{c}{1+\delta}\right)+\left(\frac{\delta \hat{\theta}}{1+\delta}-\frac{c}{1+\delta}\right)}+ \\
& \frac{\left(\widetilde{\theta}-\frac{\delta \hat{\theta}}{1+\delta}\right)\left(1-\frac{c}{1+\delta}\right) \frac{\tilde{\theta}+\frac{\delta \hat{\theta}}{1+\delta}-\frac{c}{1+\delta}}{2}+\left(\frac{\delta \widehat{\theta}}{1+\delta}-\frac{c}{1+\delta}\right) \frac{\frac{\delta \hat{\theta}}{1+\delta}-\frac{c}{1+\delta}}{2}}{\left(1-\frac{\delta \hat{\theta}}{1+\delta}\right)\left(\widetilde{\theta}-\frac{c}{1+\delta}\right)+\left(\frac{\delta \widehat{\theta}}{1+\delta}-\widetilde{\theta}+\frac{c}{1+\delta}\right)\left(\frac{\delta \hat{\theta}}{1+\delta}-\frac{c}{1+\delta}\right)+\left(\widetilde{\theta}-\frac{\delta \hat{\theta}}{1+\delta}\right)\left(1-\frac{c}{1+\delta}\right)+\left(\frac{\delta \hat{\theta}}{1+\delta}-\frac{c}{1+\delta}\right)} .
\end{aligned}
$$

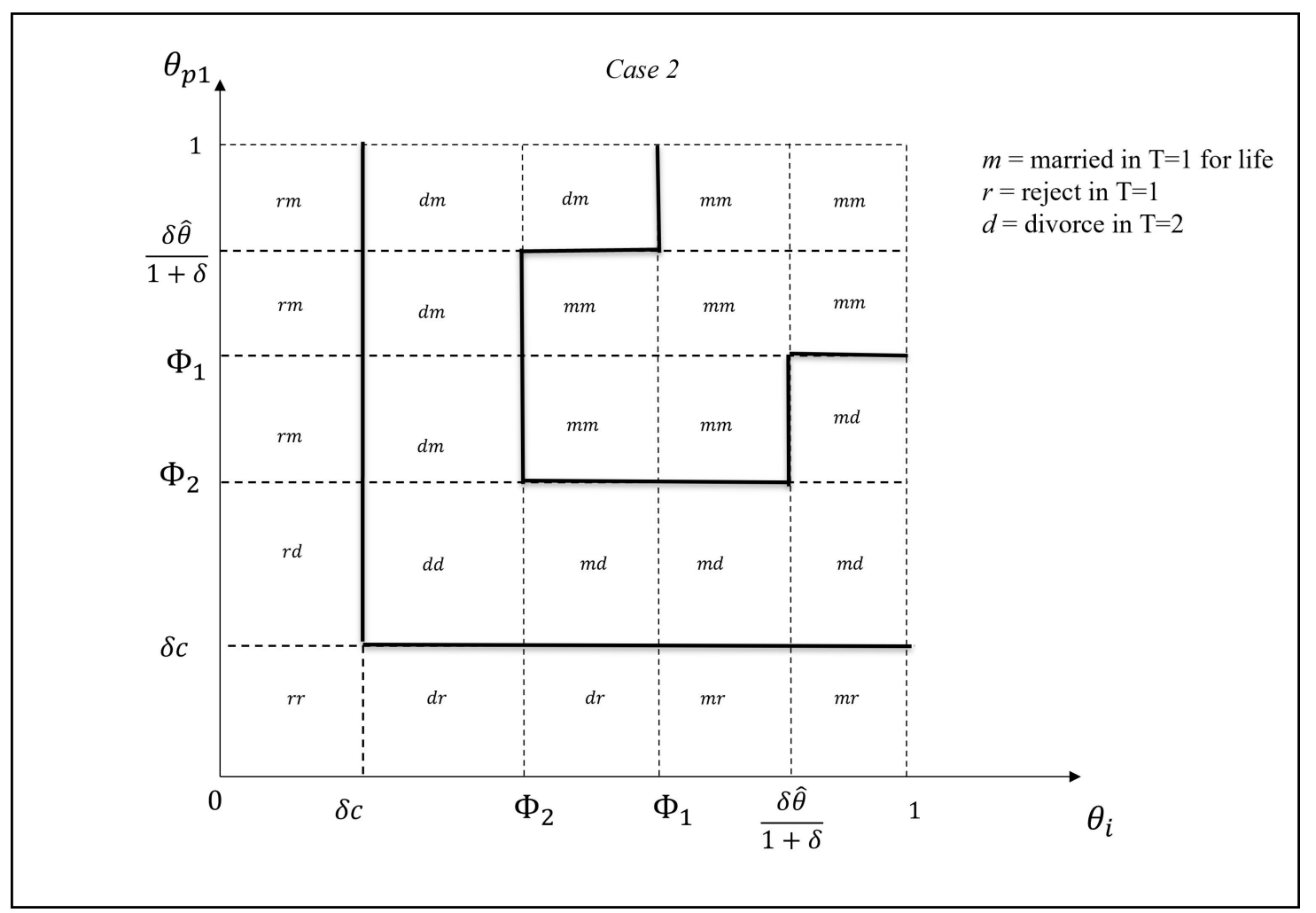

Figure A2. Equilibrium configuration for $\frac{\delta \widehat{\theta}}{1+\delta} \in\left(\Phi_{1}, \widetilde{\theta}\right)$.

In $T=3$, a single pretender is single in $T=2$ of type $>\frac{\delta \widehat{\theta}}{1+\delta}$ and has met someone of a type lower than $\frac{\delta \widehat{\theta}}{1+\delta}$ or pretenders of type $\theta_{p}<\frac{\delta \widehat{\theta}}{1+\delta}$ who, necessarily, are rejected in $T=2$; thus, they move forward to $T=3$ as singles with a probability of one. The following is obtained.

$$
\begin{aligned}
\widehat{\theta}= & \frac{\left(1-\frac{\delta \hat{\theta}}{1+\delta}\right)\left(\widetilde{\theta}-\frac{c}{1+\delta}\right) \frac{\delta \hat{\theta}}{1+\delta} \frac{\delta \hat{\theta}}{1+\delta}+1}{2}+\left(\frac{\delta \hat{\theta}}{1+\delta}-\widetilde{\theta}+\frac{c}{1+\delta}\right)\left(\frac{\delta \hat{\theta}}{1+\delta}-\frac{c}{1+\delta}\right) \frac{\tilde{\theta}-\frac{c}{1+\delta}+\frac{\delta \hat{\theta}}{1+\delta}}{2} \\
& \frac{\left(1-\frac{\delta \hat{\theta}}{1+\delta}\right)\left(\tilde{\theta}-\frac{c}{1+\delta}\right) \frac{\delta \hat{\theta}}{1+\delta}+\left(\frac{\delta \hat{\theta}}{1+\delta}-\widetilde{\theta}+\frac{c}{1+\delta}\right)\left(\frac{\delta \hat{\theta}}{1+\delta}-\frac{c}{1+\delta}\right)+\left(\widetilde{\theta}-\frac{\delta \hat{\theta}}{1+\delta}\right)\left(1-\frac{c}{1+\delta}\right)+\left(\frac{\delta \hat{\theta}}{1+\delta}-\frac{c}{1+\delta}\right)}{\left(1-\frac{\delta \hat{\theta}}{1+\delta}\right)\left(\widetilde{\theta}-\frac{c}{1+\delta}\right) \frac{\delta \hat{\theta}}{1+\delta}+\left(\frac{\delta \hat{\theta}}{1+\delta}-\widetilde{\theta}+\frac{c}{1+\delta}\right)\left(\frac{\delta \hat{\theta}}{1+\delta}-\frac{c}{1+\delta}\right)+\left(\widetilde{\theta}-\frac{\delta \hat{\theta}}{1+\delta}\right)\left(1-\frac{c}{1+\delta}\right)+\left(\frac{\delta \hat{\theta}}{1+\delta}-\frac{c}{1+\delta}\right)} .
\end{aligned}
$$

We want to show that this equilibrium configuration does not exist. To ease the exposition, we temporarily call the following. 


$$
\begin{aligned}
A_{2}= & \left(1-\frac{\delta \widehat{\theta}}{1+\delta}\right)\left(\widetilde{\theta}-\frac{c}{1+\delta}\right) \frac{\delta \widehat{\theta}}{1+\delta}+1 \\
2 & \\
B_{2}= & \left(\frac{\delta \widehat{\theta}}{1+\delta}-\widetilde{\theta}+\frac{c}{1+\delta}\right)\left(\frac{\delta \widehat{\theta}}{1+\delta}-\frac{c}{1+\delta}\right) \frac{\widetilde{\theta}-\frac{c}{1+\delta}+\frac{\delta \widehat{\theta}}{1+\delta}}{2}+\left(\widetilde{\theta}-\frac{\delta \widehat{\theta}}{1+\delta}\right)\left(1-\frac{c}{1+\delta}\right) \frac{\widetilde{\theta}+\frac{\delta \widehat{\theta}}{1+\delta}-2 \frac{c}{1+\delta}}{2} \\
& +\left(\frac{\delta \widehat{\theta}}{1+\delta}-\frac{c}{1+\delta}\right) \frac{\frac{\delta \hat{\theta}}{1+\delta}-\frac{c}{1+\delta}}{2} ; \\
C_{2}= & \left(1-\frac{\delta \widehat{\theta}}{1+\delta}\right)\left(\widetilde{\theta}-\frac{c}{1+\delta}\right) ; \\
D_{2}= & \left(\frac{\delta \widehat{\theta}}{1+\delta}-\widetilde{\theta}+\frac{c}{1+\delta}\right)\left(\frac{\delta \widehat{\theta}}{1+\delta}-\frac{c}{1+\delta}\right)+\left(\widetilde{\theta}-\frac{\delta \widehat{\theta}}{1+\delta}\right)\left(1-\frac{c}{1+\delta}\right)+\left(\frac{\delta \widehat{\theta}}{1+\delta}-\frac{c}{1+\delta}\right) .
\end{aligned}
$$

First, we need to prove that $\widetilde{\theta}>\widehat{\theta}$ :

$$
\frac{A_{2}+B_{2}}{C_{2}+D_{2}}>\frac{\frac{\delta \hat{\theta}}{1+\delta} A_{2}+B_{2}}{\frac{\delta \hat{\theta}}{1+\delta} C_{2}+D_{2}}
$$

which can be rewritten as follows.

$$
\frac{\frac{\delta \hat{\theta}}{1+\delta} C_{2}+D_{2}}{C_{2}+D_{2}}>\frac{\frac{\delta \hat{\theta}}{1+\delta} A_{2}+B_{2}}{A_{2}+B_{2}}
$$

The following can be obtained. $\frac{D_{2}}{C_{2}+D_{2}}=1-\frac{C_{2}}{C_{2}+D_{2}}$ and $\frac{B_{2}}{A_{2}+B_{2}}=1-\frac{A_{2}}{A_{2}+B_{2}}$,

$$
\frac{\frac{\delta \hat{\theta}}{1+\delta} C_{2}}{C_{2}+D_{2}}+1-\frac{C_{2}}{C_{2}+D_{2}}>\frac{\frac{\delta \widehat{\theta}}{1+\delta} A_{2}}{A_{2}+B_{2}}+1-\frac{A_{2}}{A_{2}+B_{2}} \text {. }
$$

After some manipulation, we obtain the following:

$$
\frac{A_{2}}{C_{2}}>\frac{B_{2}}{D_{2}}
$$

where $\frac{A_{2}}{C_{2}}=\frac{\frac{\delta \widehat{\theta}}{1+\delta}+1}{2}$, while defining the following.

$$
\begin{aligned}
& d_{1}=\left(\frac{\delta \widehat{\theta}}{1+\delta}-\widetilde{\theta}+\frac{c}{1+\delta}\right)\left(\frac{\delta \widehat{\theta}}{1+\delta}-\frac{c}{1+\delta}\right), \\
& d_{2}=\left(\widetilde{\theta}-\frac{\delta \widehat{\theta}}{1+\delta}\right)\left(1-\frac{c}{1+\delta}\right), \\
& d_{3}=\left(\frac{\delta \widehat{\theta}}{1+\delta}-\frac{c}{1+\delta}\right),
\end{aligned}
$$

Thus, the following can be written.

$$
\frac{B_{2}}{D_{2}}=\frac{d_{1} \frac{\tilde{\theta}-\frac{c}{1+\delta}+\frac{\delta \widehat{\theta}}{1+\delta}}{2}+d_{2} \frac{\tilde{\theta}+\frac{\delta \widehat{\theta}}{1+\delta}-2 \frac{c}{1+\delta}}{2}+d_{3} \frac{\frac{\delta \widehat{\theta}}{1+\delta}-\frac{c}{1+\delta}}{2}}{d_{1}+d_{2}+d_{3}} .
$$


If $\frac{\frac{\delta \hat{\theta}}{1+\delta}+1}{2}$ is greater than each payoff $\left(\frac{\widetilde{\theta}-\frac{c}{1+\delta}+\frac{\delta \widehat{\theta}}{1+\delta}}{2}, \frac{\widetilde{\theta}+\frac{\delta \widehat{\theta}}{1+\delta}-2 \frac{c}{1+\delta}}{2}\right.$ and $\frac{\frac{\delta \widehat{\theta}}{1+\delta}-\frac{c}{1+\delta}}{2}$, which should be true), then it is greater than a linear combination of these payoffs; thus, $\frac{A_{2}}{C_{2}}>\frac{B_{2}}{D_{2}}$.

$$
\begin{gathered}
\frac{\frac{\delta \widehat{\theta}}{1+\delta}+1}{2}>\frac{\widetilde{\theta}-\frac{c}{1+\delta}+\frac{\delta \widehat{\theta}}{1+\delta}}{2} \Leftrightarrow 1>\widetilde{\theta}-\frac{c}{1+\delta^{\prime}}, \\
\frac{\frac{\delta \widehat{\theta}}{1+\delta}+1}{2}>\frac{\widetilde{\theta}+\frac{\delta \widehat{\theta}}{1+\delta}-2 \frac{c}{1+\delta}}{2} \Leftrightarrow 1>\widetilde{\theta}-2 \frac{c}{1+\delta^{\prime}}, \\
\frac{\frac{\delta \widehat{\theta}}{1+\delta}+1}{2}>\frac{\frac{\delta \widehat{\theta}}{1+\delta}-\frac{c}{1+\delta}}{2} \Leftrightarrow 1>-\frac{c}{1+\delta} .
\end{gathered}
$$

Therefore, $\frac{A_{2}}{C_{2}}>\frac{B_{2}}{D_{2}}$, which proves that $\widetilde{\theta}>\widehat{\theta}$.

We are now in a position to evaluate whether $\widetilde{\theta}-\frac{c}{1+\delta}>\frac{\delta}{1+\delta} \widehat{\theta}$, which would produce a contradiction. This inequality can be rewritten as follows:

$$
\frac{A_{2}+B_{2}}{C_{2}+D_{2}}-\frac{c}{1+\delta}>\frac{\delta}{1+\delta} \frac{\frac{\delta \widehat{\theta}}{1+\delta} A_{2}+B_{2}}{\frac{\delta \hat{\theta}}{1+\delta} C_{2}+D_{2}},
$$

which can be rearranged as the following.

$$
\frac{A_{2}+B_{2}}{C_{2}+D_{2}}-\frac{\delta}{1+\delta} \frac{\frac{\delta \widehat{\theta}}{1+\delta} A_{2}+B_{2}}{\frac{\delta \hat{\theta}}{1+\delta} C_{2}+D_{2}}>\frac{c}{1+\delta} .
$$

Since $\widehat{\theta}<\widetilde{\theta}$, a sufficient condition is defined as follows:

$$
\begin{gathered}
\frac{A_{2}+B_{2}}{C_{2}+D_{2}}-\frac{\delta}{1+\delta} \frac{A_{2}+B_{2}}{C_{2}+D_{2}}>\frac{c}{1+\delta} \\
\frac{A_{2}+B_{2}}{C_{2}+D_{2}} \frac{1}{1+\delta}>\frac{c}{1+\delta} \Leftrightarrow \widetilde{\theta}>c,
\end{gathered}
$$

which is true by Proposition 1.

\section{Appendix C. Equilibrium Characterisation}

In this appendix, we characterise the cheap, the expensive and the highly expensive divorce equilibria.

\section{Appendix C.1. Cheap Divorce}

The cheap divorce configuration requires the following rank of the thresholds: $\Phi_{1}>$ $\frac{\delta \widehat{\theta}}{1+\delta}>\Phi_{2}>\delta c$. Single pretenders in $T=2$ are defined as follows:

- $\quad$ Eligibles of type $\theta_{p 1} \in\left(\widetilde{\theta}-\frac{c}{1+\delta}, 1\right)$ who met individuals $\theta_{i} \in\left(0, \widetilde{\theta}-\frac{c}{1+\delta}\right)$, with probability $\left(1-\widetilde{\theta}+\frac{c}{1+\delta}\right)\left(\widetilde{\theta}-\frac{c}{1+\delta}\right)$ who yield an expected payoff of $\frac{\widetilde{\theta}-\frac{c}{1+\delta}+1}{2}$;

- $\quad$ Eligibles of type $\theta_{p 1} \in\left(\frac{\delta \widehat{\theta}}{1+\delta}, \widetilde{\theta}-\frac{c}{1+\delta}\right)$ who met individuals $\theta_{i} \in(0,1)$, with probability $\left(\widetilde{\theta}-\frac{c}{1+\delta}-\frac{\delta \widehat{\theta}}{1+\delta}\right)$ who yield an expected payoff of $\frac{\widetilde{\theta}-\frac{c}{1+\delta}+\frac{\delta \widehat{\theta}}{1+\delta}}{2}$;

- Non-eligibles of type $\theta_{p 1} \in\left(\frac{\delta \widehat{\theta}}{1+\delta}-\frac{c}{1+\delta}, \frac{\delta \widehat{\theta}}{1+\delta}\right)$ who met individuals of type $\theta_{i} \in\left(0, \frac{\delta \widehat{\theta}}{1+\delta}-\frac{c}{1+\delta}\right)$ or $\theta_{i} \in\left(\frac{\delta \widehat{\theta}}{1+\delta}, 1\right)$ with probability $\frac{c}{1+\delta}\left(1-\frac{c}{1+\delta}\right)$ who yield an expected payoff of $\frac{2 \frac{\delta \widehat{\theta}}{1+\delta}-\frac{c}{1+\delta}}{2}$; 
- Non-eligibles of type $\theta_{p 1} \in\left(0, \frac{\delta \widehat{\theta}}{1+\delta}-\frac{c}{1+\delta}\right)$ who met individuals $\theta_{i} \in(0,1)$ with probability $\frac{\delta \widehat{\theta}}{1+\delta}-\frac{c}{1+\delta}$ who yield an expected payoff of $\frac{\frac{\delta \hat{\theta}}{1+\delta}-\frac{c}{1+\delta}}{2}$.

By Bayes' rule, the expected quality in $T=2$ is given by the following.

$$
\widetilde{\theta}=\frac{\left(1-\widetilde{\theta}+\frac{c}{1+\delta}\right)\left(\widetilde{\theta}-\frac{c}{1+\delta}\right) \frac{\widetilde{\theta}-\frac{c}{1+\delta}+1}{2}+\left(\widetilde{\theta}-\frac{c}{1+\delta}-\frac{\delta \widehat{\theta}}{1+\delta}\right) \frac{\widetilde{\theta}-\frac{c}{1+\delta}+\frac{\delta \hat{\theta}}{1+\delta}}{2}+\frac{c}{1+\delta}\left(1-\frac{c}{1+\delta}\right) \frac{\frac{2 \hat{\theta}}{1+\delta}-\frac{c}{1+\delta}}{2}+\left(\frac{\delta \widehat{\theta}}{1+\delta}-\frac{c}{1+\delta}\right) \frac{\frac{\delta \widehat{\theta}}{1+\delta}-\frac{c}{1+\delta}}{2}}{\left(1-\widetilde{\theta}+\frac{c}{1+\delta}\right)\left(\widetilde{\theta}-\frac{c}{1+\delta}\right)+\left(\widetilde{\theta}-\frac{c}{1+\delta}-\frac{\delta \widehat{\theta}}{1+\delta}\right)+\frac{c}{1+\delta}\left(1-\frac{c}{1+\delta}\right)+\left(\frac{\delta \widehat{\theta}}{1+\delta}-\frac{c}{1+\delta}\right)} .
$$

In $T=3$, single pretenders are single in $T=2$ and are of a type larger than $\frac{\delta \widehat{\theta}}{1+\delta}$. They have met someone of a type lower than $\frac{\delta \widehat{\theta}}{1+\delta}$ or pretenders of a type smaller than $\frac{\delta \widehat{\theta}}{1+\delta}$ who, necessarily, are rejected in $T=2$; thus, they move forward to $T=3$ as singles with a probability of one. The following is a result.

$$
\begin{aligned}
\widehat{\theta}= & \frac{\left(1-\widetilde{\theta}+\frac{c}{1+\delta}\right)\left(\widetilde{\theta}-\frac{c}{1+\delta}\right) \frac{\delta \hat{\theta}}{1+\delta} \frac{\tilde{\theta}-\frac{c}{1+\delta}+1}{2}+\left(\widetilde{\theta}-\frac{c}{1+\delta}-\frac{\delta \hat{\theta}}{1+\delta}\right) \frac{\delta \hat{\theta}}{1+\delta} \frac{\tilde{\theta}-\frac{c}{1+\delta}+\frac{\delta \hat{\theta}}{1+\delta}}{2}}{\left(1-\widetilde{\theta}+\frac{c}{1+\delta}\right)\left(\widetilde{\theta}-\frac{c}{1+\delta}\right) \frac{\delta \hat{\theta}}{1+\delta}+\left(\widetilde{\theta}-\frac{c}{1+\delta}-\frac{\delta \hat{\theta}}{1+\delta}\right) \frac{\delta \hat{\theta}}{1+\delta}+\frac{c}{1+\delta}\left(1-\frac{c}{1+\delta}\right)+\left(\frac{\delta \hat{\theta}}{1+\delta}-\frac{c}{1+\delta}\right)}+ \\
& \frac{\frac{c}{1+\delta}\left(1-\frac{c}{1+\delta}\right) \frac{2 \frac{\delta \hat{\theta}}{1+\delta}-\frac{c}{1+\delta}}{2}+\left(\frac{\delta \hat{\theta}}{1+\delta}-\frac{c}{1+\delta}\right) \frac{\frac{\delta \hat{\theta}}{1+\delta}-\frac{c}{1+\delta}}{2}}{\left(1-\tilde{\theta}+\frac{c}{1+\delta}\right)\left(\widetilde{\theta}-\frac{c}{1+\delta}\right) \frac{\delta \hat{\theta}}{1+\delta}+\left(\widetilde{\theta}-\frac{c}{1+\delta}-\frac{\delta \hat{\theta}}{1+\delta}\right) \frac{\delta \hat{\theta}}{1+\delta}+\frac{c}{1+\delta}\left(1-\frac{c}{1+\delta}\right)+\left(\frac{\delta \hat{\theta}}{1+\delta}-\frac{c}{1+\delta}\right)}
\end{aligned}
$$

Appendix C.1.1. Expensive Divorce: $\Phi_{2}<\delta c$ and $\frac{\delta \widehat{\theta}}{1+\delta} \in\left(\delta c, \Phi_{1}\right)$.

Single pretenders in $T=2$ are defined as follows:

- $\quad$ Eligibles of type $\theta_{p 1} \in\left(\widetilde{\theta}-\frac{c}{1+\delta}, 1\right)$ who met individuals $\theta_{i} \in\left(0, \widetilde{\theta}-\frac{c}{1+\delta}\right)$, with probability $\left(1-\widetilde{\theta}+\frac{c}{1+\delta}\right)\left(\widetilde{\theta}-\frac{c}{1+\delta}\right)$ who yield an expected payoff of $\frac{\widetilde{\theta}-\frac{c}{1+\delta}+1}{2}$;

- Eligibles of type $\theta_{p 1} \in\left(\frac{\delta \widehat{\theta}}{1+\delta}, \widetilde{\theta}-\frac{c}{1+\delta}\right)$ who met individuals $\theta_{i} \in(0,1)$, with probability $\left(\widetilde{\theta}-\frac{c}{1+\delta}-\frac{\delta \widehat{\theta}}{1+\delta}\right)$ who yield an expected payoff of $\frac{\widetilde{\theta}-\frac{c}{1+\delta}+\frac{\delta \widehat{\theta}}{1+\delta}}{2}$;

- Non-eligibles of type $\theta_{p 1} \in\left(\frac{\delta^{2} \widehat{\theta}}{1+\delta+\delta^{2}}, \frac{\delta \widehat{\theta}}{1+\delta}\right)$ who met individuals of type $\theta_{i} \in\left(0, \Phi_{4}\right)$ or $\theta_{i} \in\left(\frac{\delta \widehat{\theta}}{1+\delta}, 1\right)$ with probability $\left(\frac{\delta \widehat{\theta}}{1+\delta}-\frac{\delta^{2} \widehat{\theta}}{1+\delta+\delta^{2}}\right)\left(\frac{\delta^{2} \widehat{\theta}}{1+\delta+\delta^{2}}+1-\frac{\delta \widehat{\theta}}{1+\delta}\right)$ who yield an expected payoff of $\frac{\frac{\delta \hat{\theta}}{1+\delta}+\frac{\delta^{2} \hat{\theta}}{1+\delta+\delta^{2}}}{2}$;

- Non-eligibles of type $\theta_{p 1} \in\left(0, \frac{\delta^{2} \widehat{\theta}}{1+\delta+\delta^{2}}\right)$ who met individuals $\theta_{i} \in(0,1)$ with probability $\frac{\delta^{2} \widehat{\theta}}{1+\delta+\delta^{2}}$ who yield an expected payoff of $\frac{\frac{\delta^{2} \widehat{\theta}}{1+\delta+\delta^{2}}}{2}$.

By Bayes' rule, the expected quality in $T=2$ is provided by the following.

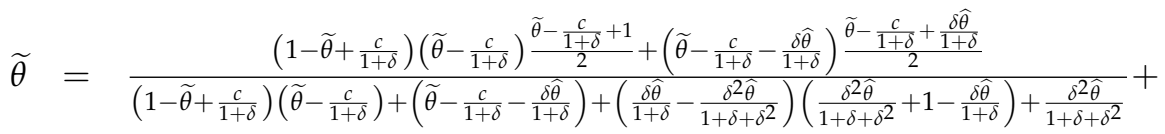

$$
\begin{aligned}
& \frac{\left(\frac{\delta \widehat{\theta}}{1+\delta}-\frac{\delta^{2} \widehat{\theta}}{1+\delta+\delta^{2}}\right)\left(\frac{\delta^{2} \hat{\theta}}{1+\delta+\delta^{2}}+1-\frac{\delta \widehat{\theta}}{1+\delta}\right) \frac{\frac{\delta \hat{\theta}}{1+\delta}+\frac{\delta^{2} \hat{\theta}}{1+\delta+\delta^{2}}}{2}+\frac{\delta^{2} \hat{\theta}}{1+\delta+\delta^{2}} \frac{\frac{\delta^{2} \hat{\theta}}{1+\delta+\delta^{2}}}{2}}{\left(1-\widetilde{\theta}+\frac{c}{1+\delta}\right)\left(\widetilde{\theta}-\frac{c}{1+\delta}\right)+\left(\widetilde{\theta}-\frac{c}{1+\delta}-\frac{\delta \hat{\theta}}{1+\delta}\right)+\left(\frac{\delta \hat{\theta}}{1+\delta}-\frac{\delta^{2} \hat{\theta}}{1+\delta+\delta^{2}}\right)\left(\frac{\delta^{2} \hat{\theta}}{1+\delta+\delta^{2}}+1-\frac{\delta \hat{\theta}}{1+\delta}\right)+\frac{\delta^{2} \hat{\theta}}{1+\delta+\delta^{2}}} .
\end{aligned}
$$


In $T=3$, single pretenders are single in $T=2$ of type $>\frac{\delta \widehat{\theta}}{1+\delta}$. They have met someone of type lower than $\frac{\delta \widehat{\theta}}{1+\delta}$ or pretenders of type $<\frac{\delta \widehat{\theta}}{1+\delta}$ who, necessarily, are rejected in $T=2$; thus, they move forward to $T=3$ as singles with a probability of one.

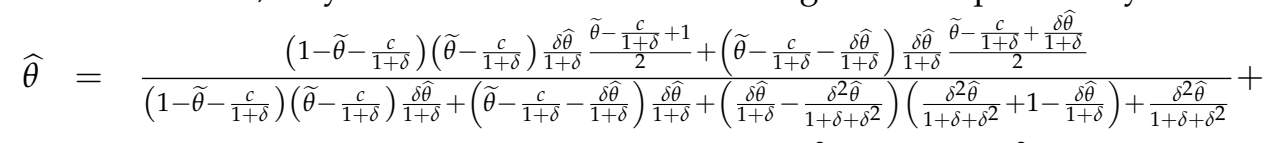

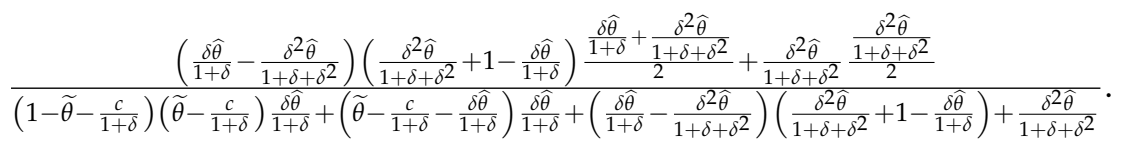

Appendix C.1.2. Highly Expensive Divorce: $\Phi_{2}<\delta c$ and $\frac{\delta \widehat{\theta}}{1+\delta}<\delta c$.

Single pretenders in $T=2$ are defined as follows:

- $\quad$ Eligibles of type $\theta_{p 1} \in\left(\widetilde{\theta}-\frac{c}{1+\delta}, 1\right)$ who met individuals $\theta_{i} \in\left(0, \widetilde{\theta}-\frac{c}{1+\delta}\right)$, with probability $\left(1-\widetilde{\theta}+\frac{c}{1+\delta}\right)\left(\widetilde{\theta}-\frac{c}{1+\delta}\right)$ who yield an expected payoff of $\frac{\widetilde{\theta}-\frac{c}{1+\delta}+1}{2}$;

- Eligibles of type $\theta_{p 1} \in\left(\frac{\delta \hat{\theta}}{1+\delta}, \widetilde{\theta}-\frac{c}{1+\delta}\right)$ who met individuals $\theta_{i} \in(0,1)$, with probability $\left(\widetilde{\theta}-\frac{c}{1+\delta}-\frac{\delta \widehat{\theta}}{1+\delta}\right)$ who yield an expected payoff of $\frac{\widetilde{\theta}-\frac{c}{1+\delta}+\frac{\delta \widehat{\theta}}{1+\delta}}{2}$;

- Non-eligibles of type $\theta_{p 1} \in\left(\frac{\delta^{2} \widehat{\theta}}{1+\delta+\delta^{2}}, \frac{\delta \widehat{\theta}}{1+\delta}\right)$ who met individuals of type $\theta_{i} \in\left(0, \frac{\delta^{2} \widehat{\theta}}{1+\delta+\delta^{2}}\right)$ or $\theta_{i} \in\left(\frac{\delta \widehat{\theta}}{1+\delta}, 1\right)$

with probability $\left(\frac{\delta \widehat{\theta}}{1+\delta}-\frac{\delta^{2} \widehat{\theta}}{1+\delta+\delta^{2}}\right)\left(\frac{\delta^{2} \widehat{\theta}}{1+\delta+\delta^{2}}+1-\frac{\delta \widehat{\theta}}{1+\delta}\right)$ who yield an expected payoff of $\frac{\frac{\delta \hat{\theta}}{1+\delta}+\frac{\delta^{2} \hat{\theta}}{1+\delta+\delta^{2}}}{2}$

- Non-eligibles of type $\theta_{p 1} \in\left(0, \frac{\delta^{2} \widehat{\theta}}{1+\delta+\delta^{2}}\right)$ who met individuals $\theta_{i} \in(0,1)$ with probability $\frac{\delta^{2} \widehat{\theta}}{1+\delta+\delta^{2}}$ who yield an expected payoff of $\frac{\frac{\delta^{2} \hat{\theta}}{1+\delta+\delta^{2}}}{2}$.

Hence, the values of $(\widetilde{\theta}, \widehat{\theta})$ are the same as in the equilibrium with expensive divorce.

\section{Appendix D}

In this appendix, we determine the expected quality of singles in $T=2$ in the twoperiods model. Figure A3 depicts the situation.

Single pretenders in $T=2$ are defined as follows:

- Of type $\theta_{p 1} \in\left(\widetilde{\theta}_{2 T}-c, 1\right)$ who met individuals $\theta_{i} \in\left(0, \widetilde{\theta}_{2 T}-c\right)$, with probability $\left(1-\widetilde{\theta}_{2 T}+c\right)\left(\widetilde{\theta}_{2 T}-c\right)$ who yield an expected payoff of $\frac{\widetilde{\theta}_{2 T}-c+1}{2}$;

- $\quad$ Of type $\theta_{p 1} \in\left(0, \widetilde{\theta}_{2 T}-c\right)$ who met individuals $\theta_{i} \in(0,1)$, with probability $\widetilde{\theta}_{2 T}-c$ who yield an expected payoff of $\frac{\widetilde{\theta}_{2 T}-c}{2}$;

By using Bayes' rule and the process of simplification, the expected quality in $T=2$ is given by the following.

$$
\widetilde{\theta}_{2 T}=\frac{\left(1-\widetilde{\theta}_{2 T}+c\right) \frac{\tilde{\theta}_{2 T}-c+1}{2}+\frac{\tilde{\theta}_{2 T}-c}{2}}{\left(1-\widetilde{\theta}_{2 T}+c\right)+1} .
$$

By solving for $\widetilde{\theta}_{2 T}$ and rearranging, we obtain the following.

$$
\widetilde{\theta}_{2 T}=\frac{3-\sqrt{5+4 c+4 c^{2}}}{2} .
$$




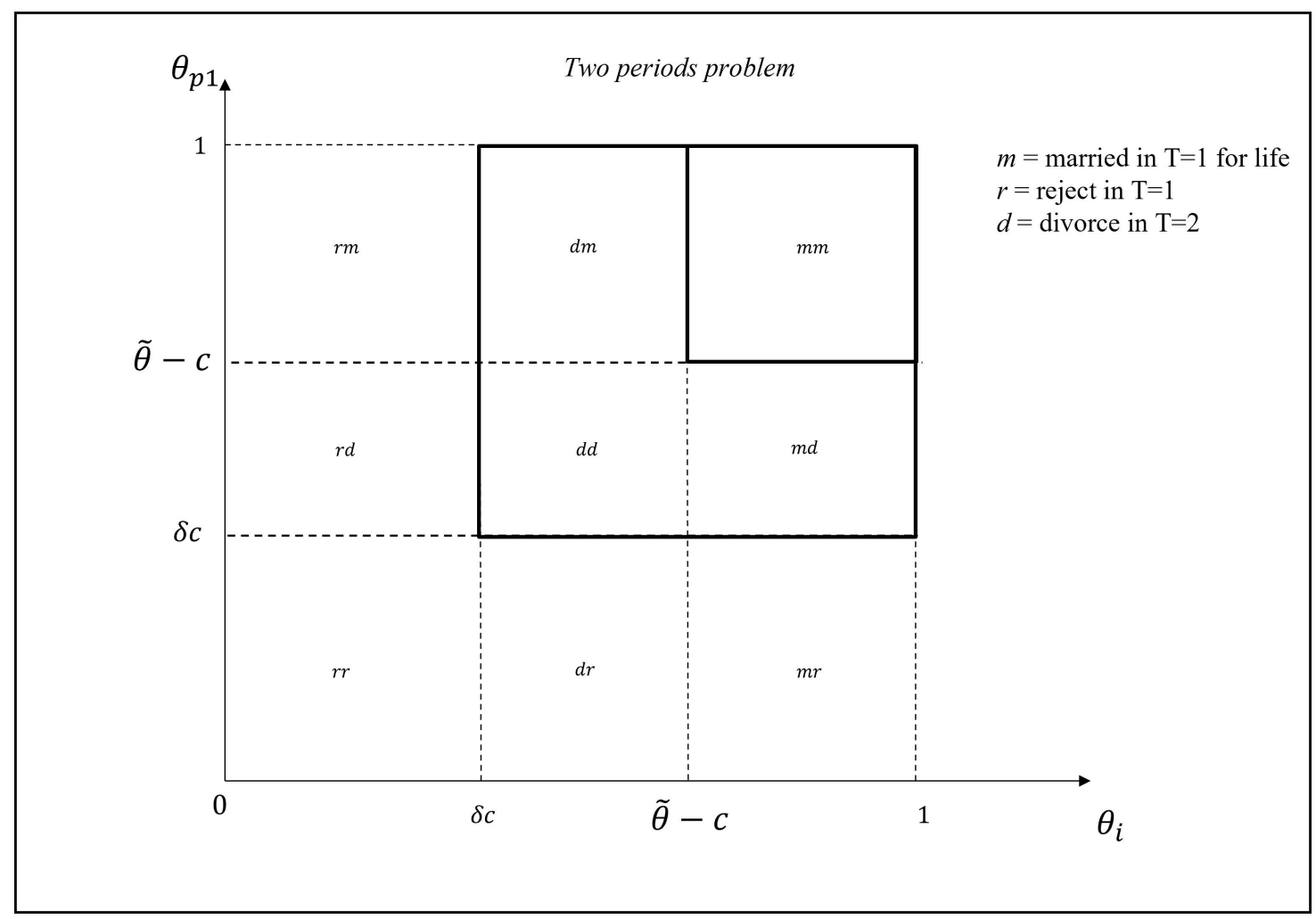

Figure A3. Divorce equilibrium in a 2-periods setting.

\section{References}

1. Osborne, M.J. An Introduction to Game Theory; Oxford University Press: New York, NY, USA, 2004; Volume 3.

2. Kahneman, D.; Tversky, A. Prospect Theory: An Analysis of Decision under Risk. Econometrica 1979, 47, 263-291. [CrossRef]

3. Gronchi, G.; Giovannelli, F. Dual process theory of thought and default mode network: A possible neural foundation of fast thinking. Front. Psych. 2018, 9, 1237. [CrossRef]

4. Gibbons, R.S. Game Theory for Applied Economists; Princeton University Press: Princeton, NJ, USA, 1992.

5. Genesove, D.; Han, L. Search and matching in the housing market. J. Urb. Econ. 2012, 72, 31-45. [CrossRef]

6. Daly, M.C.; Hobijn, B.; Şahin, A.; Valletta, R.G. A search and matching approach to labor markets: Did the natural rate of unemployment rise? J. Econ. Persp. 2012, 26, 3-26. [CrossRef]

7. Lundberg, S.; Pollak, R.A. Bargaining and distribution in marriage. J. Econ. Perspect. 1996, 10, 139-158. [CrossRef]

8. Rasul, I. Marriage market and divorce laws. J. Law. Econ. Org. 2006, 22, 30-69. [CrossRef]

9. Peters, H.E. Marriage and Divorce: Reply. Am. Econ. Rev. 1992, 82, 687-693.

10. Chiappori, P.A.; Fortin, B; Lacroix, G. Marriage market, divorce legislation, and household labor supply. J. Polit. Econ. 2002, 110, 37-72. [CrossRef]

11. Matouschek, N.; Rasul, I. The economics of the marriage contract: Theories and evidence. J. Law. Econ. 2008, 51, 59-110. [CrossRef]

12. Stevenson, B. The impact of divorce laws on marriage-specific capital. J. Labor Econ. 2007, 25, 75-94. [CrossRef]

13. Cigno, A. Marriage as a commitment device. Rev. Econ. Househ. 2012, 10, 193-213. [CrossRef]

14. Shimer, R.; Smith, L. Assortative matching and search. Econometrica 2000, 68, 343-369. [CrossRef]

15. Biernat, M. Standard and Expectancies: Contrast and Assimilation in Judgments of Self and Others; Psychology Press: Hove, UK, 2005.

16. Pierguidi, L.; Righi, S.; Gronchi, G.; Marzi, T.; Caharel, S.; Giovannelli, F.; Viggiano, M.P. Emotional contexts modulate intentional memory suppression of neutral faces: Insights from ERPs. Int. J. Psychophisiol. 2016, 106, 1-13. [CrossRef] [PubMed]

17. Righi, S.; Gronchi, G.; Marzi, T.; Rebai, M.; Viggiano, M.P. You are that smiling guy I met at the party! Socially positive signals foster memory for identities and contexts. Acta Psychol. 2015, 159, 1-7. [CrossRef]

18. Parducci, A. The relativism of absolute judgments. Sci. Am. 1968, 219, 84-90. [CrossRef]

19. Norton, A.J.; Glick, P.C. Marital instability: Past, present and future. J. Soc. Issues 1976, 32, 5-20. [CrossRef]

20. Livingston, G. Tying the Knot Again? Chances Are, There's a Bigger Age Gap Than the First Time Around. Pew Research Center. 2014. Available online: https://www.pewresearch.org/fact-tank/2014/12/04/tying-the-knot-again-chances-are-theresa-bigger-age-gap-than-the-first-time-around/ (accessed on 1 November 2021). 
21. Chiappori, P.A.; Weiss, Y. Divorce, remarriage and welfare: A general equilibrium approach. J. Eur. Econ. Assoc. $2009,4,415-426$. [CrossRef]

22. Goldmanis, M.; Ray, K.; Stuart, E. Until death do us part? The marriage model with divorce. Work. Pap. $2012,24,1-25$.

23. Smith, L. Cross-sectional dynamics in a two-sided matching model. Univ. Chic. Univ. Mich. Mimeo 1992, 14, 10-56.

24. Shimer, R.; Smith, L. Nonstationary search. Univ. Chic. Univ. Mich. Mimeo 2000, 1, 1-34.

25. Damiano, E.; Li, H.; Suen, W. Unraveling of dynamic sorting. Rev. Econ. Stud. 2005, 53, 1057-1076. [CrossRef]

26. Bonneton, N.; Sandmann, C. Non-stationary search and assortative matching. Work. Pap. 2019, 1, 1-48.

27. Burdett, K.; Coles, M. Marriage and class. Q. J. Econ. 1997, 112, 141-168. [CrossRef]

28. Burdett, K.; Coles, M. Long-term partnership formation: Marriage and employment. Econ. J. 1999, 109, 307-334. [CrossRef]

29. Eeckhout, J. Bilateral search and vertical heterogeneity. Int. Econ. Rev. 1999, 40, 869-887. [CrossRef]

30. Bloch, F.; Ryder, H. Two-sided search, marriages, and matchmakers. Int. Econ. Rev. 1999, 41, 93-115. [CrossRef]

31. Chade, H. Two-sided search and perfect segregation with fixed search costs. Math. Soc. Sci. 2001, 42, 31-51. [CrossRef]

32. Smith, L. The marriage model with search frictions. J. Pol. Econ. 2006, 114, 1124-1144. [CrossRef]

33. Coles, M.G.; Francesconi, M. On the emergence of toyboys: The timing of marriage with aging and uncertain careers. Int. Econ. Rev. 2011, 52, 825-853. [CrossRef]

34. Murray, S. How broadband and cell phone access have impacted marriage and divorce in the US. Rev. Econ. Househ. 2020, 18, 431-459. [CrossRef]

35. Chiappori, P.A. The theory and empirics of the marriage market. Ann. Rev. Econ. 2020, 12, 547-578. [CrossRef]

36. Marinescu, I. Divorce: What does learning have to do with it? Labour Econ. 2016, 38, 90-105. [CrossRef]

37. Barham, V.; Devlin, R.A.; Yang, J. A theory of rational marriage and divorce. Eur. Econ. Rev. 2009, 53, 90-106. [CrossRef]

38. Bolletta, U.; Merlino, L.P. Marriage through Friends. arXiv 2021, arXiv:2111.03825.

39. Chow, Y.S.; Robbins, H.; Siegmund, D. Great Expectations: The Theory of Optimal Stopping; Houghton Mifflin Company: Boston, MA, USA, 1971.

40. McNamara, J.; Collins, E. The job-search problem as an empolyer-candidate game. J. Appl. Prob. 1990, 28, 815-827. [CrossRef]

41. Ramsey, D.M. A Game Theoretic Model of Choosing a Valuable Good via a Short List Heuristic. Mathematics 2020, 8, 199. [CrossRef]

42. Coles, M.G.; Francesconi, M. Equilibrium Search with Multiple Attributes and the Impact of Equal Opportunities for Women. J. Pol. Econ. 2019, 127, 138-162. [CrossRef]

43. Booth, A.; Amato, P.R.; Johnson, D.R.; Edwards, J.N. Marital Instability Over the Life Course: Methodology Report for the Fifth Wave; University of Nebraska Bureau of Sociological Research: Lincoln, NE, USA, 1993.

44. Salganik M.J.; Dodds P.S.; Watts D.J. Experimental study of inequality and unpredictability in an artificial cultural market. Science 2006, 311, 854-856. [CrossRef]

45. Cohen M.J.; Brezis M.; Block C.; Diederich A.; Chinitz D. Vaccination, herd behavior, and herd immunity. Med. Decis. Making 2013, 33, 1026-1038. [CrossRef]

46. Camerer, C.F. Behavioral Game Theory; Russel Sage Foundation: New York, NY, USA, 2003.

47. Oaksford, M.; Chater, N. Bayesian Rationality; Oxford University Press: Oxford, UK, 2007.

48. Griffiths, T.L.; Chater, N.; Kemp, C.; Perfors, A.; Tenenbaum, J.B. Probabilistic models of cognition: Exploring representations and inductive biases. Trends Cogn. Sci. 2010, 14, 357-364. [CrossRef] [PubMed]

49. Griffiths, T.L.; Tenenbaum, J.B. Statistics and the Bayesian mind. Signif 2006, 3, 130-133. [CrossRef]

50. Marr, D. Vision: A Computationa Approach; The MIT Press: Cambridge, UK, 1982.

51. Suchow, J.W.; Bourgin, D.D.; Griffiths, T.L. Evolution in mind: Evolutionary dynamics, cognitive processes, and Bayesian inference. Trends Cogn. Sci. 2017, 21, 522-530. [CrossRef] [PubMed]

52. Kahneman, D.; Slovic, P.; Tversky, A. Judgment under Uncertainty: Heuristics and Biases; Cambridge University Press: Cambridge, UK, 1982.

53. González-Val, R.; Marcén, M. Breaks in the breaks: An analysis of divorce rates in Europe. Int. Rev. Law Econ. 2012, 32, $242-255$. [CrossRef]

54. Ventura, J.; Reed, M. Divorce for Dummies; Wiley Publisher: Hoboken, NJ, USA, 2009.

55. Marcassa, S. Divorce law and divorce rate in the U.S. B.E. J. Macroeconon 2013, 13, 1-39. [CrossRef]

56. Wolfers, J. Did unilateral divorce laws raise divorce rates? A reconciliation and new results. Am. Econ. Rev. 2006, 96, 1802-1820. [CrossRef]

57. González, L.; Viitanen T.K. The effect of divorce laws on divorce rates in Europe. Eur. Econ. Rev. 2009, 53, 127-138. [CrossRef]

58. Friedberg, L. Did unilateral divorce raise divorce rates? Evidence from panel data. Am. Econ. Rev. 1998, 88, 608-27.

59. Allen, D.W. Marriage and divorce: Comment. Am. Econ. Rev. 1992, 82, 679-685.

60. Peters, H.E. Marriage and divorce: Informational constraints and private contracting. Am. Econ. Rev. 1986, 76, 437-454.

61. Cohen, P.N. The coming divorce decline. Socius 2019, 5, 1-6. [CrossRef]

62. Petrongolo, B.; Pissarides, C.A. Looking into the black box: A survey of the matching function. J. Econ. Lit. 2001, 39, 390-431. [CrossRef]

63. Reyna, V.F.; Nelson, W.L.; Han, P.K.; Pignone, M.P. Decision making and cancer. Am. Psych. 2015, 70, 105-118. [CrossRef] [PubMed] 
64. Church, J.; Saunders, D.; Wanke, M.; Pong, R.; Spooner, C.; Dorgan, M. Citizen participation in health decision-making: Past experience and future prospects. J. Public Health Policy 2002, 23, 12-32. [CrossRef]

65. Glerum, P.J.; Maliepaard, M.; de Valk, V.; Burger, D.M.; Neef, K. Drug switching in The Netherlands: A cohort study of 20 active substances. BMC Health Serv. Res. 2020, 20, 1-10. [CrossRef] [PubMed]

66. Linton, D.; Procyshyn, R.M.; Elbe, D.; Lee, L.H.N.; Barr, B.M. A retrospective study of antipsychotic drug switching in a pediatric population. BMC Psychiatry 2013, 13, 248. [CrossRef]

67. Fishbein, M.; Ajzen, I. Theory-based behavior change interventions: Comments on Hobbis and Sutton. J. Health Psychol. 2005, 10, 27-31. [CrossRef]

68. Jha, A.K.; DesRoches, C.M.; Campbell, E.G.; Donelan, K.; Rao, S.R.; Ferris, T.G.; Shields, A.; Rosenbaum, S.; Blumenthal, D. Use of electronic health records in US hospitals. N. Eng. J. Med. 2019, 360, 1628-1638. [CrossRef]

69. Cianferotti, L.; Parri, S.; Gronchi, G.; Marcucci, G.; Cipriani, C.; Pepe, J.; Raglianti, M.; Minisola, S.; Brandi, M.L. Prevalence of chronic hypoparathyroidism in a Mediterranean region as estimated by the analysis of anonymous healthcare database. Calcif. Tissue Int. 2018, 103, 144-150. [CrossRef]

70. Giudici, F.; Cavalli, T.; Giusti, F.; Gronchi, G.; Batignani, G.; Tonelli, F.; Brandi, M.L. Natural history of MEN1 GEP-NET: Single-center experience after a long follow-up. World J. Surg. 2017, 41, 2312-2323. [CrossRef]

71. Hennessy, S. Use of health care databases in pharmacoepidemiology. Basic Clin. Pharmacol. Toxicol. 2006, 98, 311-313. [CrossRef]

72. Becker, G.S. A theory of marriage: Part I. J. Pol. Econ. 1973, 81, 813-846. [CrossRef] 